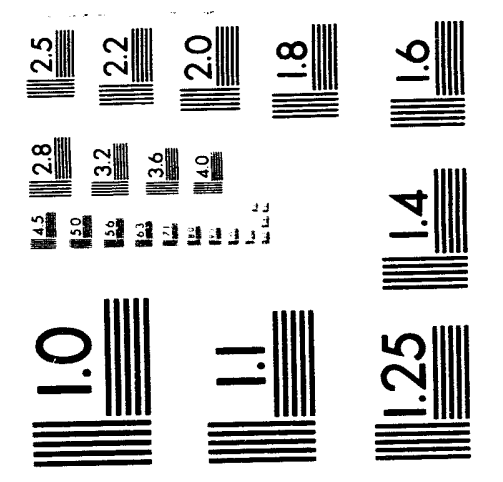



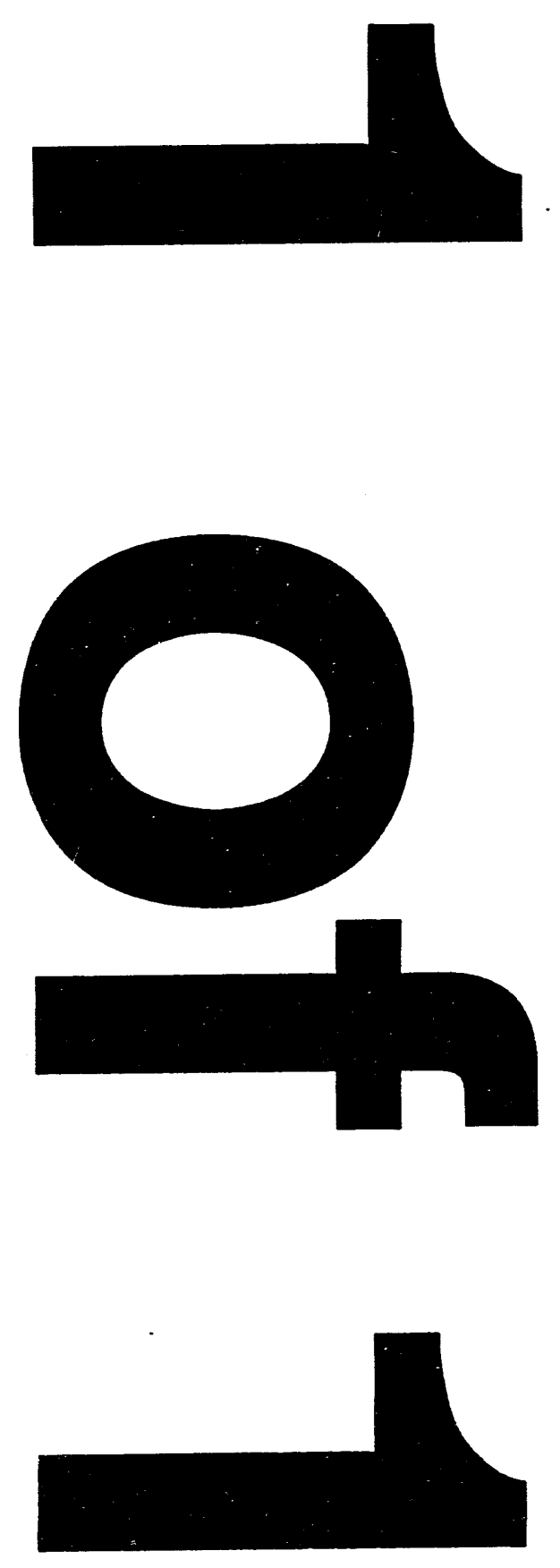
BOMAB Phantom Manufacturing

Quality Assurance Study Using

Monte Carlo Computations

Michael W. Mallett 


\title{
BOMAB PHANTOM MANUFACTURING QUALITY ASSURANCE STUDY USING MONTE CARLO COMPUTATIONS
}

\author{
by
}

Michael W. Mallett

\begin{abstract}
Monte Carlo calculations have been performed to assess the importance of and quantify quality assurance protocols in the manufacturing of the Bottle-Manikin-Absorption (BOMAB) phantom for calibrating in vivo measurement systems. The parameters characterizing the BOMAB phantom that were examined included height, fill volume, fill material density, wall thickness, and source concentration. Transport simulation was performed for monoenergetic photon sources of $0.200,0.662$, and $1.460 \mathrm{MeV}$. A linear response was observed in the photon current exiting the exterior surface of the $\mathrm{BOMAB}$ phantom due to variations in these parameters. Sensitivity studies were also performed for an in vivo system in operation at the Pacific Northwest Laboratories in Richland, WA. Variations in detector current for this in vivo system are reported for changes in the BOMAB phantom parameters studied here. Physical justifications for the observed results are also discussed.
\end{abstract}

\section{INTRODUCTION}

A study is currently being performed to assess the importance of quality assurance protocols in the manufacturing of the Bottle-Manikin-Absorption (BOMAB) phantom for calibrating in vivo measurement systems. The BOMAB phantom is a surrogate hurnan structure used to calibrate an in vivo measurement system specifically for a whole body distribution of radioactivity. The phantom consists of ten hollow bottles which are right 
circular cylinders or right elliptical cylinders in shape, each representing a different section of the human body as shown in Fig. 1. The walls are constructed of 4.76-mm-thick highdensity polyethylene, and may be filled with appropriate tissue substitute materials. The dimensions of the standard BOMAB phantom representing the average adult male human body are given in Table 1.

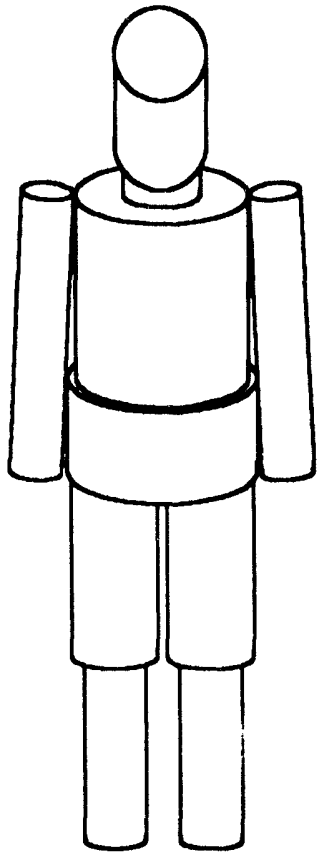

Fig. 1. The BottleManikin-Absorption (BOMAB) Phantom.
Table 1. Standard BOMAB Phantom Dimensions for the Average Adult Male Human Body.

$\begin{array}{ccccc}\begin{array}{c}\text { Bottle/body } \\ \text { section }\end{array} & \begin{array}{c}\text { Cylinder } \\ \text { shape }\end{array} & \begin{array}{c}\text { Cross } \\ \text { section } \\ (\mathrm{cm})\end{array} & \begin{array}{c}\text { Vertical } \\ \text { height } \\ (\mathrm{cm})\end{array} & \begin{array}{c}\text { Fill } \\ \text { volume } \\ \left(\mathrm{cm}^{3}\right)\end{array}\end{array}$

$\begin{array}{llccc}\text { Head } & \text { Right elliptical } & 19 \times 14 & 20 & 3523 \\ \text { Neck } & \text { Right circular } & 13 & 10 & 1032 \\ \text { Thorax } & \text { Right elliptical } & 30 \times 20 & 40 & 16,969 \\ \text { Pelvis } & \text { Right elliptical } & 36 \times 20 & 20 & 9987 \\ \text { Thigh (2) } & \text { Right circular } & 15 & 40 & 6052 \text { (ea) } \\ \text { Leg (2) } & \text { Right circular } & 12 & 40 & 3743 \text { (ea) } \\ \text { Arm (2) } & \text { Right circular } & 10 & 60 & 3797 \text { (ea) }\end{array}$

All walls are composed of 4.76-mm-thick high-density polyethylene.

The study is being conducted by utilizing Monte Carlo methods to sample photon fields emanating from radioactive sources distributed among the ten BOMAB phantom bottles. The general-purpose Monte Carlo code MCNP, Version 4, developed at the Los Alamos National Laboratory (LANL) is used to perform the computations (Briesmeister and Hendricks 1991). The development of the method for performing radiation transport computations using MCNP with regard to the BOMAB phantom has been given previously (Mallett 1993a). Further modifications to the MCNP code itself have been 
made to better facilitate Monte Carlo computations utilizing the BOMAB phantom design, in addition to improving the detail of the geometry model and accuracy of the sampling techniques used (Mallett 1993b). The purpose of this paper is to publish a portion of the results of this study rather than to describe the modified MCNP code. Hence, the literature should be consulted for specific details regarding development and implementation of the revised code.

This study involves varying the parameters that characterize the BOMAB phantom and then observing the resulting change in photon current at the exterior surface of the phantom. A study of the sensitivity of particular in vivo measurement systems to changes in the characteristic BOMAB parameters is also being performed. The objective of this facet of the study is to better understand and assess the applicability of the standard BOMAB phantom towards supplying generic system calibration efficiencies for the entire measurement population at a given facility. Those in vivo measurement systems included in the study are located at LANL, the Sandia National Laboratories (SNL) in Albuquerque, NM, and the Pacific Northwest Laboratories (PNL) in Richland, WA. Each facility represents a different detector system design in the measurement of whole body distributed radionuclides. This report contains the Monte Carlo results for the PNL in vivo measurement system only. The Monte Carlo results estimating the BOMAB phantom exterior surface current are also presented.

The PNL in vivo measurement system consists of five NaI scintillation detectors as shown in Fig. 2. Four of these detectors are $24 \mathrm{~cm}$ in diameter; one is $29 \mathrm{~cm}$ in diameter. Each crystal is $10 \mathrm{~cm}$ thick. The detector system is located posterior to the upright subject during the measurement. The detectors are mounted such that the face of each is tangent to a common plane $2.5 \mathrm{~cm}$ from the posterior surface of the subject, in this case the BOMAB phantom. In addition, a 1.3-cm-thick Plexiglas plate is located in the space 

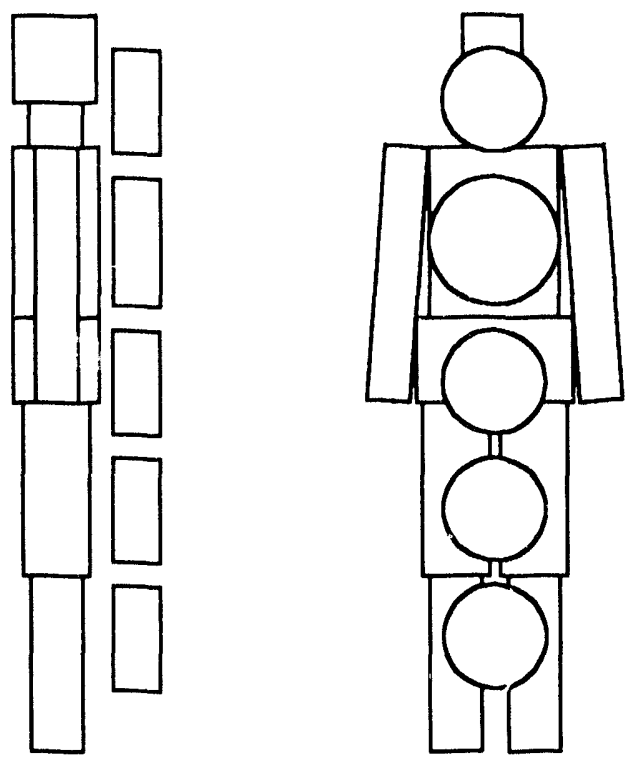

Fig. 2. The BOMAB phantom positioned for calibration of the five-NaI-detector in vivo system currently operated at PNL. The phantom is configured in the "centerline" geometry (i.e., a common axis or plane passes through the center of each bottle in the vertical direction). Four of the detectors are $24 \mathrm{~cm}$ in diameter; one is $29 \mathrm{~cm}$ in diameter. Each detector is $10 \mathrm{~cm}$ in thickness.

between the subject and the detectors. The BOMAB phantom was configured in the "centerline" geometry (i.e., positioned along a central axis common to all bottles) for calibration of the PNL detector system as shown in Fig. 2.

\section{DESCRIPTION OF EXPERIMENTS}

The change in photon current at the exterior surface of the BOMAB phantom and the subsequent variation in detector current for the in vivo measurement systems studied here were observed by varying parameters characterizing the structure of the phantom. Each experiment discussed below describes the parameter of interest and the degree to which it was varied, as well as additional constraints regarding the BOMAB structure that were imposed for each test. The notation used to define characteristic parameters is 
shown in Fig. 3, including the standard dimension and the modified value. The notation includes the following:

a: one-half the axis in the defined $\hat{x}$ direction,

$\mathrm{b}$ : one-half the axis in the defined $\hat{y}$ direction,

z: height in the defined $\hat{z}$ direction,

t: wall thickness,

1. denotes inner dimension, and

*. denotes modified dimension.

The modified values of these and other pertinent parameters for each experiment are listed in Appendix A.

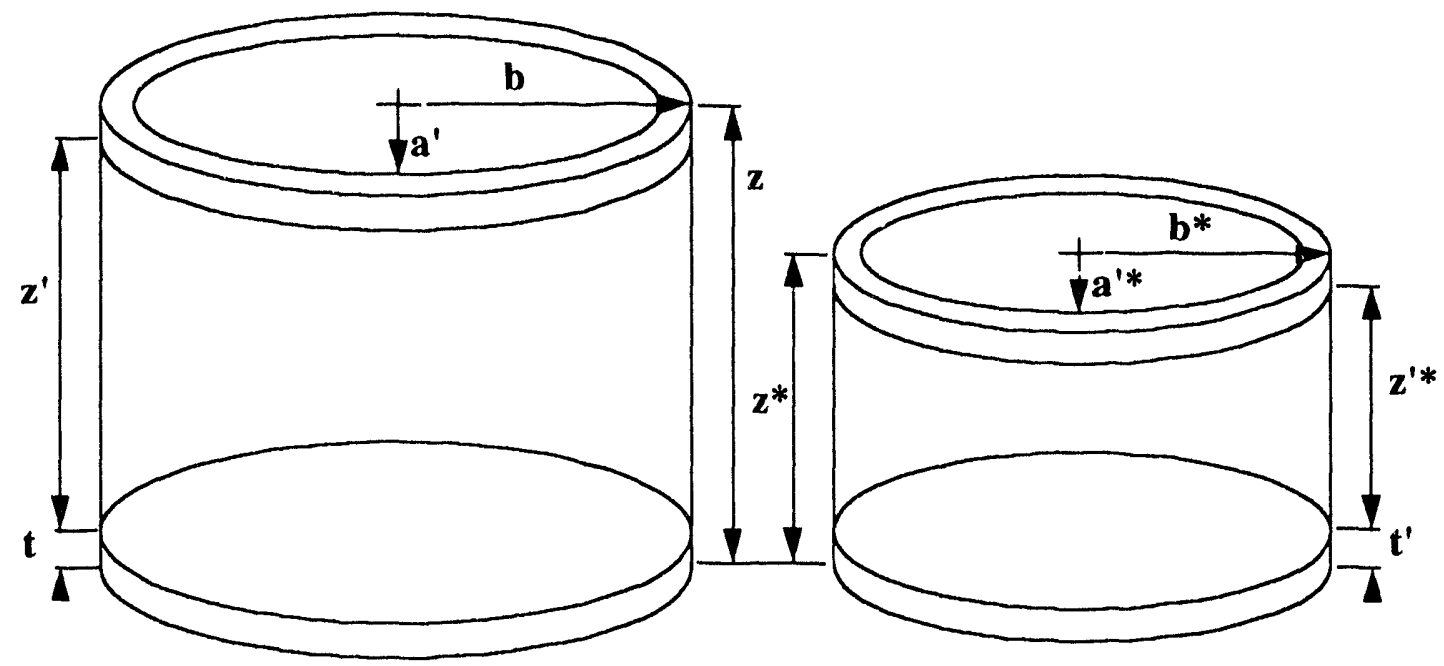

Fig. 3. Diagram of notation used to describe the BOMAB phantom characteristic parameters: $\mathbf{a}, \mathbf{b}$, and $\mathbf{z}$ refer to measurements in the defined $\hat{x}-, \hat{y}-$, and $\hat{z}$-axis directions, respectively. Other notations include the following: $\mathbf{t}$ denotes wall thickness, ' refers to inner dimensions, and ${ }^{*}$ refers to a modified dimension different from the value listed in Table 1.

Experiment \#1. Vary the height.

The height ( $\mathrm{z}$ ) of each bottle was varied by $\pm 5 \%, \pm 10 \%$, and $\pm 20 \%$. In each case, the fill volume of the bottle, given by: 


$$
\text { Fill Volume }=a^{\prime *} \times b^{\prime *} \times z^{\prime *} \times \pi,
$$

was held constant (see Fig. 3). In order to hold the fill volume constant, an additional restraint was required:

$$
\frac{a^{\prime}}{a^{\prime *}}=\frac{b^{\prime}}{b^{\prime *}} \text {. }
$$

Experiment \#2. Vary the fill volume.

The fill volume given in Eq. (1) was varied by $\pm 5 \%, \pm 10 \%$, and $\pm 20 \%$. This was performed by two methods:

Experiment \#2A required holding the height of each bottle constant while varying the parameters defining the fill volume according to Eq. (2).

Experiment \#2B permitted the height of each bottle to change such that

$$
\frac{a^{\prime}}{a^{\prime *}}=\frac{b^{\prime}}{b^{\prime *}}=\frac{z^{\prime}}{z^{\prime *}}
$$

Experiment \#3. Vary the density of the fill material.

The density of the fill material was varied by $\pm 5 \%, \pm 10 \%$, and $\pm 20 \%$. This was performed by varying the density of two fill materials, specifically polyurethane and water.

Experiment \#3A used polyurethane, standard density $\rho=1.09 \mathrm{~g} \mathrm{~cm}^{-3}$, as the fill material.

Experiment \#3B used water, standard density $\rho=1.00 \mathrm{~g} \mathrm{~cm}^{-3}$, as the fill material.

Experiment \#4. Vary the wall thickness.

The walls of each standard phantom bottle are composed of 4.76-mm-thick highdensity polyethylene $\left(\rho=0.95 \mathrm{~g} \mathrm{~cm}^{-3}\right)$. The wall thickness was varied by $\pm 5 \%, \pm 10 \%$, and $\pm 20 \%$, as well as increased to $10 \mathrm{~mm}$. The fill volume was held constant in each case.

Experiment \#5. Vary the source concentration of the fill material.

The source concentration of the fill material was varied by $\pm 5 \%, \pm 10 \%$, and $\pm 20 \%$. This was rerformed by three methods: 
Experiment \#5A varied the source concentration of the thorax bottle.

Experiment \#5B varied the source concentration of the pelvis bottle.

Experiment $\# 5 \mathrm{C}$ varied the source concentration of the thorax, pelvis, and arm bottles proportionately.

In each case, polyurethane $\left(\rho=1.09 \mathrm{~g} \mathrm{~cm}^{-3}\right)$ was used as the fill material (Griffith $e t$ al. 1978).

\section{DATA REPORTING}

The Monte Carlo computation results using the modified MCNP code for each experiment described above are tabulated in Appendix B and displayed graphically in Appendix C. The results for Experiment \#1 are also reported in Table 2 and are shown graphically in Figs. 4-6 to facilitate interpretation of the reporting protocol and photon sampling techniques used by the code. Recall, Experiment \#1 varied the height of each bottle while holding the fill volume constant.

The Monte Carlo computations were performed individually for source photons having an energy of $0.200,0.662$, and $1.460 \mathrm{MeV}$. The source photons were distributed uniformly throughout the total fill volume of the phantom, except as specified in Experiments \#5A-C. Hence, the source concentration (source particles $\mathrm{cm}^{-3}$ ) was identical within each bottle. The data plotted in Fig. 4 are the Monte Carlo results of sampling source energy photons crossing the exterior surface of the BOMAB phantom, normalized per source photon (i.e., the relative surface current.) The exterior surface of the $\mathrm{BOMAB}$ phantom is defined as the total surface area of the phantom bottles not overlapped by adjacent bottles. For example, the neck bottle has two end surfaces completely overlapped by the end surfaces of the adjacent head and thorax bottles. Hence, the neck bottle contribution to the total exterior surface area of the phantom 
Table 2. Monte Carlo Results for Different Phantom Heights (Experiment \#1).

Relative BOMAB surface current

(source energy photons/source photon)

$\begin{array}{ccccccc}\text { \% change } & 200 \mathrm{keV} & 3 \sigma & 662 \mathrm{keV} & 3 \sigma & 1460 \mathrm{keV} & 3 \sigma \\ -20 \% & 0.331710 & 0.004478 & 0.453070 & 0.004757 & 0.557120 & 0.004680 \\ -10 \% & 0.342120 & 0.004516 & 0.464040 & 0.004733 & 0.567740 & 0.004769 \\ -5 \% & 0.347160 & 0.004478 & 0.469450 & 0.004788 & 0.572730 & 0.004639 \\ 0 \% & 0.352097 & 0.001479 & 0.473819 & 0.001564 & 0.577123 & 0.001558 \\ 5 \% & 0.357260 & 0.004501 & 0.479270 & 0.004745 & 0.582470 & 0.004718 \\ 10 \% & 0.361840 & 0.004559 & 0.484300 & 0.004795 & 0.587490 & 0.004582 \\ 20 \% & 0.370410 & 0.004556 & 0.493160 & 0.004734 & 0.596460 & 0.004652\end{array}$

Relative PNL in vivo system detector current

(source energy photons incident upon detectors/source photon)

$\begin{array}{ccccccc}\text { \% change } & 200 \mathrm{keV} & 3 \sigma & 662 \mathrm{keV} & 3 \sigma & 1460 \mathrm{keV} & 3 \sigma \\ -20 \% & 0.043379 & 0.000612 & 0.060375 & 0.000706 & 0.075330 & 0.000791 \\ -10 \% & 0.047599 & 0.000643 & 0.065636 & 0.000748 & 0.081459 & 0.000831 \\ -5 \% & 0.047973 & 0.000648 & 0.065900 & 0.000751 & 0.081506 & 0.000831 \\ 0 \% & 0.048046 & 0.000202 & 0.065956 & 0.000237 & 0.081499 & 0.000269 \\ 5 \% & 0.048361 & 0.000638 & 0.066000 & 0.000752 & 0.081492 & 0.000831 \\ 10 \% & 0.048355 & 0.000638 & 0.065939 & 0.000752 & 0.081114 & 0.000827 \\ 20 \% & 0.046934 & 0.000634 & 0.063681 & 0.000726 & 0.077889 & 0.000794\end{array}$

Relative PNL 29-cm NaI detector current

(source energy photons incident upon $29-\mathrm{cm} \mathrm{Nal}$ detector/source photon)

$\begin{array}{ccccccc}\% \text { change } & 200 \mathrm{keV} & 3 \sigma & 662 \mathrm{keV} & 3 \sigma & 1460 \mathrm{keV} & 3 \sigma \\ -20 \% & 0.013213 & 0.000341 & 0.018628 & 0.000408 & 0.023501 & 0.000451 \\ -10 \% & 0.016134 & 0.000378 & 0.022721 & 0.000450 & 0.028653 & 0.000499 \\ -5 \% & 0.016549 & 0.000382 & 0.023253 & 0.000453 & 0.029302 & 0.000510 \\ 0 \% & 0.016479 & 0.000119 & 0.023265 & 0.000140 & 0.029343 & 0.000158 \\ 5 \% & 0.016490 & 0.000381 & 0.023082 & 0.000450 & 0.029140 & 0.000507 \\ 10 \% & 0.016247 & 0.000380 & 0.022818 & 0.000445 & 0.028652 & 0.000499 \\ 20 \% & 0.015639 & 0.000371 & 0.021919 & 0.000441 & 0.027361 & 0.000492\end{array}$


consists strictly of the side surface area (i.e., the circumference times the height.) Additionally, the exterior surface areas of the two adjacent bottles are reduced by the surface area equal to the end surfaces of the neck bottle.

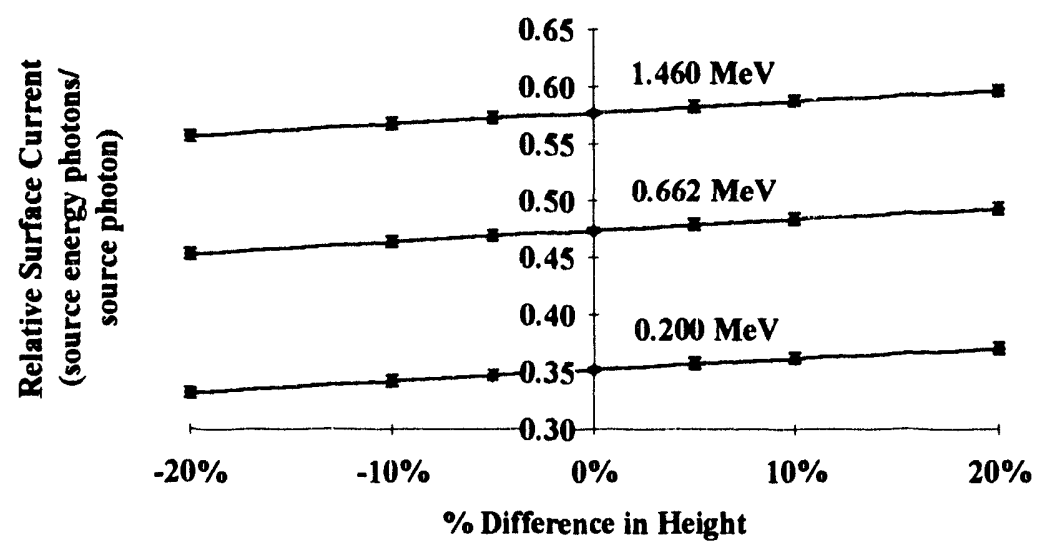

Fig. 4. Relative BOMAB surface current Monte Carlo results for different phantom heights (Experiment $\# 1$ ). Errors shown are $\pm 3 \sigma$.

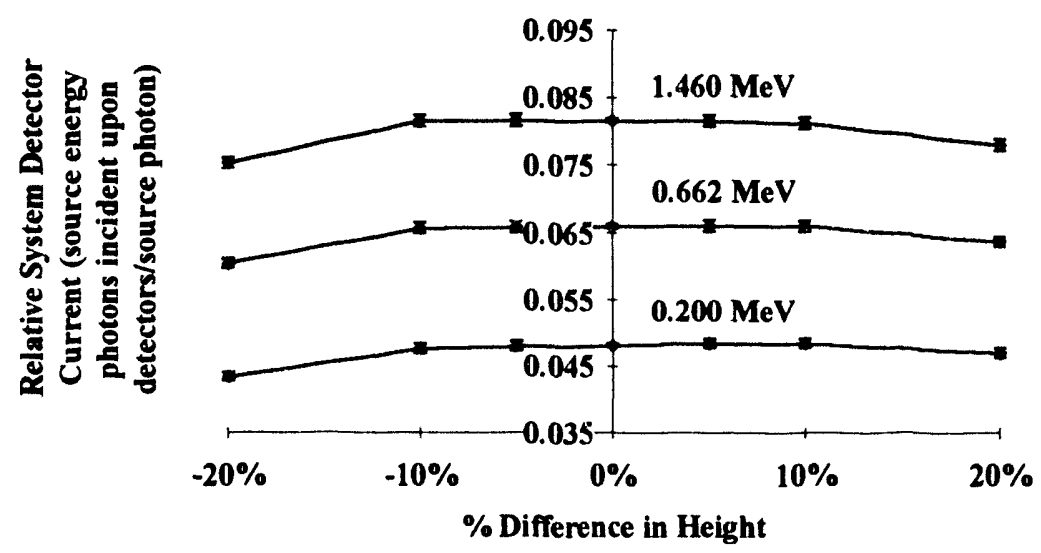

Fig. 5. Relative PNL in vivo system detector current Monte Carlo results for different phantom heights (Experiment \#1). Errors shown are $\pm 3 \sigma$. 


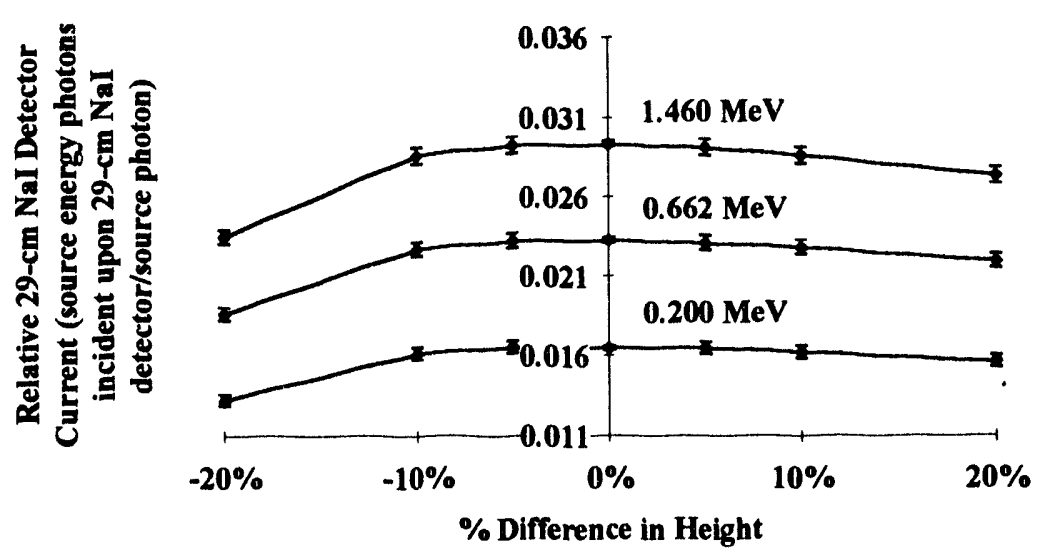

Fig. 6. Relative PNL 29-cm NaI detector current Monte Carlo results for different phantom heights (Experiment \#1). Errors shown are $\pm 3 \sigma$.

The Monte Carlo results of Fig. 4 were estimated by tallying photons using a 2 $\mathrm{keV}$-wide energy bin below the source energy. For example, a photon having a source energy of $0.200 \mathrm{MeV}$ was tallied at the exterior surface of the phantom if it emerged with an energy between 0.198 and $0.200 \mathrm{MeV}$. Each data point for the experiment was determined by processing 100,000 source photons. However, the data points for $0 \%$ change in height (i.e., $0 \%$ change in all parameters) represent the Monte Carlo results for the standard $\mathrm{BOMAB}$ phantom of the dimensions given in Table 1, and were determined by sampling $1,000,000$ source photons. The error reported for each data point is $\pm 3 \sigma$ based on the relative error estimated by MCNP. Results are for the centerline geometry configuration as previously noted.

The results shown in Figs. 5 and 6 are specific to the PNL in vivo measurement system described above. The data plotted in Fig. 5 are the Monte Carlo results of sampling source energy photons incident upon one of the five detectors. The Monte Carlo results are normalized per source photon, and thus represent the relative detector current for the in vivo system. The tallies were compiled using a $2 \mathrm{keV}$-wide energy bin below the source energy. Figure 6 displays the Monte Carlo results solely for the $29-\mathrm{cm} \mathrm{NaI}$ 
detector. Each data point for the experiment was determined by processing $1,000,000$ source photons. The data points for the standard BOMAB phantom dimensions (i.e., $0 \%$ change) were determined by sampling $10,000,000$ source photons. The error reported for each data point is $\pm 3 \sigma$ based on the relative error estimated by MCNP. Results are for the centerline geometry configuration as previously noted.

The data displayed in Figs. 5 and 6 should not be confused with the absolute detection efficiency of the system. The Monte Carlo results presented here must be corrected by an appropriately determined intrinsic efficiency (counts per $\gamma$ incident) for each detector in order to determine the absolute detection efficiency of the system (Mallett 1993c). However, the Monte Carlo results represent a means by which to compare changes in the relative sensitivity of the in vivo measurement system for a given variation in the BOMAB parameters. This comparison requires making the reasonable assumption that the intrinsic efficiency of each detector is unaffected by the changes in the BOMAB phantom construction studied here.

\section{DISCUSSION}

The Monte Carlo results presented in Appendices B and C reflect physical aspects of the calibration process that warrant discussion. First, the photon current for the exterior surface of the BOMAB phantom is shown to be a linear function of the percentage difference in each of the sensitivity studies performed here. This fact is evident in Fig. 4 for Experiment \#1 in which the height of the phantom was varied. In this instance, the linear response may be easily understood by considering the change in surface area $(\mathrm{S})$ relative the volume $(\mathrm{V})$ for each bottle. It has been shown that the mean chord length (L) for a convex volume is equal to $4 \mathrm{~V} / \mathrm{S}$ (ICRU 1980). Table 3 reports the exterior surface area, the fill volume (held constant), and the mean chord length of each 
bottle as a function of the change in the height of the phantom for Experiment \#1. Note that a slight error has been introduced due to the calculation of the mean chord length using the exterior surface area rather than the surface of the fill volume. However, the following results show this error to be insignificant in relating changes in the calculated mean chord length to changes in the surface current.

The variation in the mean chord length for the entire $\mathrm{BOMAB}$ phantom at each percentage change in height is of interest. However, it is the attenuation of the source photons for the given mean chord length of each bottle that must be considered. The effective mean chord length for the entire BOMAB phantom, $\mathrm{L}_{\mathrm{eff}}$, may be calculated by exponentially averaging the mean chord length in each bottle, as given by

$$
\mathrm{L}_{\mathrm{eff}}=\left(\frac{-1}{\mu_{\mathrm{E}_{\gamma}}}\right) \times \ln \left[\sum \exp \left(-\mu_{\mathrm{E}_{\gamma}} \times \mathrm{L}_{i}\right)\right]
$$

where $\mu_{E_{\gamma}}$ is the linear attenuation coefficient for polyurethane at $E_{\gamma}$ (ICRU 1989). Table 3 reports the effective mean chord length for each change in the height of the phantom at each photon energy studied here. Similarly, the effective mean attenuation by the phantom is given by

$$
\text { effective mean attenuation }=\sum \exp \left(-\mu_{\mathrm{E}_{\gamma}} \times \mathrm{L}_{i}\right) .
$$

The effective mean attenuation is reported in Table 3 and is also displayed graphically in Fig. 7. The linear change in the effective mean attenuation that is evident in Fig. 7 can be inferred as the physical justification for the linear change in the BOMAB surface current observed in Fig. 4. Similar findings are true for the remaining experiments in which either $L_{\text {eff }}$ or $\mu_{\mathrm{E}_{\gamma}}$ was varied. 
Table 3. Experiment \#1 Physical Parameters Defining Mean Attenuation.

Exterior surface area

\begin{tabular}{lrrrrrrrr} 
Bottle & $-20 \%$ & $-10 \%$ & \multicolumn{1}{c}{$-5 \%$} & \multicolumn{1}{c}{$(\mathrm{cm})$} & $5 \%$ & $10 \%$ & $20 \%$ & \multicolumn{1}{c}{$\begin{array}{c}\text { Volume } \\
\left(\mathrm{cm}^{3}\right)\end{array}$} \\
& & & & & & & & \\
head & 1292.4 & 1310.4 & 1321.5 & 1333.7 & 1346.7 & 1360.4 & 1389.4 & 3523.0 \\
neck & 367.0 & 388.1 & 398.4 & 408.4 & 418.3 & 428.0 & 446.9 & 1031.5 \\
thorax & 3283.0 & 3412.5 & 3477.5 & 3542.3 & 3607.0 & 3671.3 & 3798.8 & 16968.9 \\
pelvis & 2034.9 & 2082.3 & 2108.6 & 2136.0 & 2164.3 & 2193.3 & 2252.8 & 9987.4 \\
thigh (ea) & 1758.9 & 1855.3 & 1902.3 & 1948.6 & 1994.1 & 2038.9 & 2126.6 & 6052.3 \\
leg (ea) & 1481.1 & 1551.5 & 1586.4 & 1621.1 & 1655.4 & 1689.5 & 1756.6 & 3743.3 \\
arm (ea) & 1865.2 & 1954.1 & 1998.2 & 2042.0 & 2085.6 & 2128.8 & 2214.1 & 3796.6
\end{tabular}

Mean chord length

$\begin{array}{lrrrrrrr}\text { Bottle } & -20 \% & -10 \% & -5 \% & 0 \% & 5 \% & 10 \% & 20 \% \\ & & & & & & & \\ \text { head } & 10.9 & 10.8 & 10.7 & 10.6 & 10.5 & 10.4 & 10.1 \\ \text { neck } & 11.2 & 10.6 & 10.4 & 10.1 & 9.9 & 9.6 & 9.2 \\ \text { thorax } & 20.7 & 19.9 & 19.5 & 19.2 & 18.8 & 18.5 & 17.9 \\ \text { pelvis } & 19.6 & 19.2 & 18.9 & 18.7 & 18.5 & 18.2 & 17.7 \\ \text { thigh (ea) } & 13.8 & 13.0 & 12.7 & 12.4 & 12.1 & 11.9 & 11.4 \\ \text { leg (ea) } & 10.1 & 9.7 & 9.4 & 9.2 & 9.0 & 8.9 & 8.5 \\ \text { arm (ea) } & 8.1 & 7.8 & 7.6 & 7.4 & 7.3 & 7.1 & 6.9\end{array}$

\begin{tabular}{|c|c|c|c|c|c|c|c|c|}
\hline \multirow{2}{*}{$\begin{array}{l}\text { Energy } \\
(\mathrm{MeV})\end{array}$} & \multicolumn{7}{|c|}{ Effective mean chord length } & \multirow{2}{*}{$\begin{array}{c}\mu / \rho \\
\left(\mathrm{cm}^{2} \mathrm{~g}^{-1}\right)\end{array}$} \\
\hline & $-20 \%$ & $-10 \%$ & $-5 \%$ & $0 \%$ & $5 \%$ & $10 \%$ & $20 \%$ & \\
\hline 0.200 & 11.60 & 11.14 & 10.93 & 10.72 & 10.53 & 10.34 & 9.99 & 0.134 \\
\hline 0.667 & 11.94 & 11.46 & 11.24 & 11.03 & 10.82 & 10.63 & 10.27 & 0.0845 \\
\hline 1.460 & 12.15 & 11.66 & 11.43 & 11.22 & 11.01 & 10.81 & 10.44 & 0.0574 \\
\hline
\end{tabular}

Effective mean attenuation

Energy (unattenuated source energy photons/source photon)

$\begin{array}{llllllll}(\mathrm{MeV}) & -20 \% & -10 \% & -5 \% & 0 \% & 5 \% & 10 \% & 20 \%\end{array}$

$\begin{array}{llllllll}0.200 & 0.1836 & 0.1964 & 0.2026 & 0.2088 & 0.2149 & 0.2209 & 0.2325\end{array}$

$\begin{array}{lllllllll}0.667 & 0.3330 & 0.3479 & 0.3551 & 0.3621 & 0.3690 & 0.3757 & 0.3885\end{array}$

$\begin{array}{lllllllll}1.460 & 0.4677 & 0.4821 & 0.4890 & 0.4957 & 0.5022 & 0.5085 & 0.5205\end{array}$ 


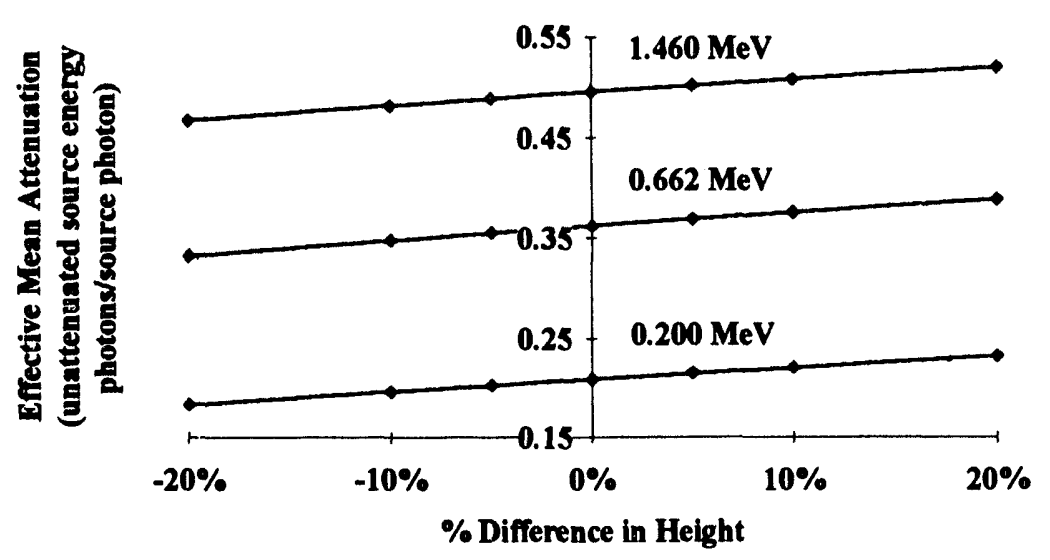

Fig. 7. Effective mean attenuation by the BOMAB phantom for different phantom heights (Experiment \#1).

Monte Carlo results specific to the PNL in vivo measurement system are included in Appendices B and C. The results of Experiment \#1 for the entire system as well as for the 29-cm NaI detector only are shown graphically in Figs. 5 and 6, respectively. The data shown in Fig. 5 indicate that the sensitivity of the PNL system is relatively independent of changes in height except at relatively extreme values (i.e., $\pm 20 \%$ ). That is, variations in the phantom height by $\pm 10 \%$ (i.e., ranging in height from $153-187 \mathrm{~cm}$ ) result in no detectable change in the sensitivity of the PNL in vivo system. Similarly, the data shown in Fig. 6 reflect the relatively stable detector current of the $29-\mathrm{cm} \mathrm{NaI}$ detector except at extreme heights.

Figures 5 and 6 show that the $29-\mathrm{cm} \mathrm{NaI}$ detector is responsible for $\sim 35 \%$ of the PNL in vivo system detector current for this geometry. Hence, this study demonstrates the capability of using these Monte Carlo computations to assess the appropriate position of the 29-cm NaI detector in the PNL in vivo system with respect to variations in the height of subjects. Similar data for each detector and for a variety of phantom (or subject) characteristics could therefore be used to optimize the entire in vivo system design. 
Monte Carlo results for the remaining experiments specific to the PNL in vivo system and the $29-\mathrm{cm} \mathrm{NaI}$ detector alone are included in Appendices B and C of this report. Changes in the source concentration of particular bottles (i.e., thorax, pelvis, and arms) performed in Experiments \#5A-C indicate little variation in the overall system sensitivity. However, the relative detector current of the $29-\mathrm{cm} \mathrm{NaI}$ detector is obviously dependent upon the distribution of the source, and is particularly sensitive to variations in the source concentration of the thorax bottle (see Appendices B and C). This is to be expected given the position of the $29-\mathrm{cm} \mathrm{NaI}$ detector relative to the bottles with varied concentrations investigated here. The results for Experiments \#2-4 show a significant

relationship between the PNL in vivo system sensitivity and the particular BOMAB parameter considered in each case. This dependence can be attributed to a more significant change in self-absorption (i.e., dependence on $\mathrm{L}_{\mathrm{eff}}$ ) for a given percentage change in the $\mathrm{BOMAB}$ parameter, as compared with an identical percentage change in the height of the phantom (Experiment \#1.) Also, the effective distance between the photon source origin and the detectors varies more for a given percentage change in the BOMAB parameters studied in Experiments \#2-4 than for the same percentage change in the height of the phantom.

\section{CONCLUSIONS}

The Monte Carlo code MCNP, modified for directly handling the BOMAB phantom, was used to examine the importance of quality assurance protocols in the manufacturing of the BOMAB phantom with applicability to calibrating in vivo measurement systems. Sensitivity studies indicated a linear dependence of the photon current exiting the $\mathrm{BOMAB}$ phantom exterior surface as a function of those parameters characterizing the phantom studied here, specifically, height, fill volume, fill material density, wall thickness, and source concentration. Hence, quality assurance protocols in 
the production of the $\mathrm{BOMAB}$ phantom are essential to ensuring consistent (or at least acceptable) standard photon fields emanating from the surface of mass-produced phantoms. The determination of appropriate quality controls can therefore be based on the linear response of the photon fields to variations in these BOMAB parameters.

The sensitivity studies also showed the dependence of the PNL in vivo system on variations in the phantom parameters. Changes in the sensitivity of the system were not observed to be linear in all cases. Hence, quality assurance protocols must be determined based on the specific in vivo system design considered. Towards this end, the Monte Carlo methods utilized here are useful in assessing the relative changes in the sensitivity of the system to given changes in the BOMAB phantom design. Similarly, this technique is an excellent means for determining the appropriateness of applying calibration efficiencies produced using the standard $\mathrm{BOMAB}$ phantom to the entire population at a given facility. For example, the standard BOMAB phantom-determined calibration efficiency for the PNL system is applicable to all subjects differing only in height within the range $153-187$ $\mathrm{cm}$. However, this calibration efficiency should not be applied to subjects well outside this height range. Similar conclusions regarding varying other BOMAB parameters must likewise be considered relative to the particular in vivo system design.

\section{ACKNOWLEDGMENTS}

PNL in vivo measurement system data were provided by Timothy P. Lynch, PNL. This manuscript was graciously reviewed by Robert W. Keys III and Hsiao-Hua Hsu of Health Physics Measurements, HS-4, and by Ileana Buican, Writing and Editing, IS-1, Los Alamos National Laboratory. 


\section{REFERENCES}

Briesmeister, J. F.; Hendricks, J. S. MCNP4 Newsletter. Los Alamos, NM: Los Alamos National Laboratory; X-6:JFB-91-177; 1991.

Griffith, R. V.; Dean, P. N.; Anderson, A. L.; Fisher, J. C. Fabrication of a TissueEquivalent Torso Phantom for Intercalibration of In-Vivo Transuranic-Nuclide Counting Facilities. Livermore, CA: Lawrence Livermore Laboratory; UCRL-80343; 1978.

International Commission on Radiation Units and Measurements. Radiation Quantities and Units. Washington, D.C.: ICRU; ICRU Report 33; 1980.

International Commission on Radiation Units and Measurements. Tissue Substitutes in Radiation Dosimetry and Measurement. Bethesda, MD: ICRU; ICRU Report 44; 1989.

Mallett, M. W. In Vivo Measurement System Calibration Using Magnetic Resonance Imaging and Monte Carlo Computations. College Station, TX: Texas A\&M University; 1993a. Ph.D. Dissertation.

Mallett, M. W. Calibration of In Vivo Measurement Systems with the BOMAB Phantom Using Monte Carlo Computations. Los Alamos, NM: Los Alamos National Laboratory; LA-UR-93-4256; 1993 b.

Mallett, M. W. A Three-Point Method for Absolutely Determining the Intrinsic Efficiency of a Photon Detector Using Monte Carlo Computations. Los Alamos, NM: Los Alamos National Laboratory; LA-UR-93-3896; 1993 c. 


\section{APPENDIX A. BOMAB PARAMETERS}

\section{Experiment \#1}

Vary the height of the phantom.

$\%$ difference in height $=-20 \%$

\begin{tabular}{lrcrrrrrrrr} 
bottle & \multicolumn{1}{c}{$\mathrm{a}$} & $\mathrm{a}^{\prime}$ & \multicolumn{1}{c}{$\mathrm{a}^{*}$} & \multicolumn{1}{c}{$\mathrm{b}$} & \multicolumn{1}{c}{$\mathrm{b}^{\prime}$} & $\mathrm{b}^{*}$ & $\mathbf{z}$ & $\mathbf{z}^{\prime}$ & $\mathbf{z}^{*}$ & $\mathrm{t}$ \\
head & 9.5 & 9.024 & 10.629 & 7.0 & 6.524 & 7.816 & 20.0 & 19.048 & 16.000 & 0.476 \\
neck & 6.5 & 6.024 & 7.301 & 6.5 & 6.024 & 7.301 & 10.0 & 9.048 & 8.000 & 0.476 \\
thorax & 10.0 & 9.524 & 11.157 & 15.0 & 14.524 & 16.764 & 40.0 & 39.048 & 32.000 & 0.476 \\
pelvis & 10.0 & 9.524 & 11.191 & 18.0 & 17.524 & 20.192 & 20.0 & 19.048 & 16.000 & 0.476 \\
thigh (ea) & 7.5 & 7.024 & 8.353 & 7.5 & 7.024 & 8.353 & 40.0 & 39.048 & 32.000 & 0.476 \\
leg (ea) & 6.0 & 5.524 & 6.671 & 6.0 & 5.524 & 6.671 & 40.0 & 39.048 & 32.000 & 0.476 \\
arm (ea) & 5.0 & 4.524 & 5.544 & 5.0 & 4.524 & 5.544 & 60.0 & 59.048 & 48.000 & 0.476
\end{tabular}

Referring to Fig. 3, the relationship of the additional parameters listed above (e.g., a, a', and $b^{\prime}$, etc.) is straightforward. Therefore, these parameters are not listed in the remaining tables of Appendix A.

$\%$ difference in height $=-10 \%$

\begin{tabular}{lrrrc} 
bottle & \multicolumn{1}{c}{$\mathrm{a}^{*}$} & \multicolumn{1}{c}{$\mathrm{b}^{*}$} & \multicolumn{1}{c}{$\mathrm{z}^{*}$} & $\mathrm{t}$ \\
head & 10.015 & 7.372 & 18.000 & 0.476 \\
neck & 6.863 & 6.863 & 9.000 & 0.476 \\
thorax & 10.529 & 15.806 & 36.000 & 0.476 \\
pelvis & 10.543 & 18.999 & 18.000 & 0.476 \\
thigh (ea) & 7.890 & 7.890 & 36.000 & 0.476 \\
leg (ea) & 6.307 & 6.307 & 36.000 & 0.476 \\
arm (ea) & 5.249 & 5.249 & 54.000 & 0.476
\end{tabular}

$\%$ difference in height $=-5 \%$

\begin{tabular}{lrrrc} 
bottle & \multicolumn{1}{c}{$\mathrm{a}^{*}$} & \multicolumn{1}{c}{$\mathrm{b}^{*}$} & \multicolumn{1}{c}{$\mathrm{z}^{*}$} & $\mathrm{t}$ \\
head & 9.747 & 7.178 & 19.000 & 0.476 \\
neck & 6.674 & 6.674 & 9.500 & 0.476 \\
thorax & 10.254 & 15.387 & 38.000 & 0.476 \\
pelvis & 10.260 & 18.479 & 19.000 & 0.476 \\
thigh (ea) & 7.687 & 7.687 & 38.000 & 0.476 \\
leg (ea) & 6.147 & 6.147 & 38.000 & 0.476 \\
arm (ea) & 5.119 & 5.119 & 57.000 & 0.476
\end{tabular}

All distances are reported in $\mathrm{cm}$. Unless otherwise specified, $\mathrm{t}=\mathrm{t}^{*}$ 
Experiment \#1 (cont.)

Vary the height of the phantom.

$\%$ difference in height $=5 \%$

$\begin{array}{lrrrc}\text { bottle } & \mathrm{a}^{*} & \mathrm{~b}^{*} & \mathrm{z}^{*} & \mathbf{t} \\ \text { head } & 9.272 & 6.835 & 21.000 & 0.476 \\ \text { neck } & 6.340 & 6.340 & 10.500 & 0.476 \\ \text { thorax } & 9.765 & \mathbf{i} 4.642 & 42.000 & 0.476 \\ \text { pelvis } & 9.759 & 17.557 & 21.000 & 0.476 \\ \text { thigh (ea) } & 7.327 & 7.327 & 42.000 & 0.476 \\ \text { leg (ea) } & 5.864 & 5.864 & 42.000 & 0.476 \\ \text { arm (ea) } & 4.889 & 4.889 & 63.000 & 0.476\end{array}$

$\%$ difference in height $=10 \%$

\begin{tabular}{lrrrc} 
bottle & $\mathrm{a}^{*}$ & \multicolumn{1}{c}{$\mathrm{b}^{*}$} & $\mathrm{z}^{*}$ & $\mathrm{t}$ \\
head & 9.061 & 6.682 & 22.000 & 0.476 \\
neck & 6.192 & 6.192 & 11.000 & 0.476 \\
thorax & 9.547 & 14.309 & 44.000 & 0.476 \\
pelvis & 9.536 & 17.147 & 22.000 & 0.476 \\
thigh (ea) & 7.166 & 7.166 & 44.000 & 0.476 \\
leg (ea) & 5.737 & 5.737 & 44.000 & 0.476 \\
arm (ea) & 4.786 & 4.786 & 66.000 & 0.476
\end{tabular}

$\%$ difference in height $=20 \%$

\begin{tabular}{lrrrc} 
bottle & $\mathrm{a}^{*}$ & \multicolumn{1}{c}{$\mathbf{b}^{*}$} & $\mathbf{z}^{*}$ & $\mathbf{t}$ \\
head & 8.680 & 6.407 & 24.000 & 0.476 \\
neck & 5.928 & 5.928 & 12.000 & 0.476 \\
thorax & 9.153 & 13.708 & 48.000 & 0.476 \\
pelvis & 9.134 & 16.407 & 24.000 & 0.476 \\
thigh (ea) & 6.875 & 6.875 & 48.000 & 0.476 \\
leg (ea) & 5.508 & 5.508 & 48.000 & 0.476 \\
arm (ea) & 4.600 & 4.600 & 72.000 & 0.476
\end{tabular}




\section{Experiment \#2A}

Vary the fill volume of the phantom; hold the height constant.

$\%$ difference in fill volume $=-20 \%$

\begin{tabular}{lrrrc} 
bottle & $\mathrm{a}^{*}$ & \multicolumn{1}{c}{$\mathrm{b}^{*}$} & $\mathbf{z}^{*}$ & $\mathrm{t}$ \\
head & 8.547 & 6.311 & 20.000 & 0.476 \\
neck & 5.864 & 5.864 & 10.000 & 0.476 \\
thorax & 8.995 & 13.467 & 40.000 & 0.476 \\
pelvis & 8.995 & 16.150 & 20.000 & 0.476 \\
thigh (ea) & 6.758 & 6.758 & 40.000 & 0.476 \\
leg (ea) & 5.417 & 5.417 & 40.000 & 0.476 \\
arm (ea) & 4.522 & 4.522 & 60.000 & 0.476
\end{tabular}

$\%$ difference in fill volume $=-10 \%$

$\begin{array}{lrrrc}\text { bottle } & \mathrm{a}^{*} & \mathrm{~b}^{*} & \mathrm{z}^{*} & \mathrm{t} \\ \text { head } & 9.037 & 6.665 & 20.000 & 0.476 \\ \text { neck } & 6.191 & 6.191 & 10.000 & 0.476 \\ \text { thorax } & 9.511 & 14.255 & 40.000 & 0.476 \\ \text { pelvis } & 9.511 & 17.101 & 20.000 & 0.476 \\ \text { thigh (ea) } & 7.140 & 7.140 & 40.000 & 0.476 \\ \text { leg (ea) } & 5.717 & 5.717 & 40.000 & 0.476 \\ \text { arm (ea) } & 4.768 & 4.768 & 60.000 & 0.476\end{array}$

$\%$ difference in fill volume $=-5 \%$

$\begin{array}{lrrrc}\text { bottle } & \mathrm{a}^{*} & \mathrm{~b}^{*} & \mathrm{z}^{*} & \mathrm{t} \\ \text { head } & 9.272 & 6.835 & 20.000 & 0.476 \\ \text { neck } & 6.347 & 6.347 & 10.000 & 0.476 \\ \text { thorax } & 9.759 & 14.632 & 40.000 & 0.476 \\ \text { pelvis } & 9.759 & 17.556 & 20.000 & 0.476 \\ \text { thigh (ea) } & 7.322 & 7.322 & 40.000 & 0.476 \\ \text { leg (ea) } & 5.860 & 5.860 & 40.000 & 0.476 \\ \text { arm (ea) } & 4.885 & 4.885 & 60.000 & 0.476\end{array}$

All distances are reported in $\mathrm{cm}$. Unless otherwise specified, $\mathrm{t}=\mathrm{t}^{*}$. 
Experiment \#2A (cont.)

Vary the fill volume of the phantom; hold the height constant.

$\%$ difference in fill volume $=5 \%$

\begin{tabular}{lrrcc} 
bottle & $\mathrm{a}^{*}$ & \multicolumn{1}{c}{$\mathrm{b}^{*}$} & $\mathbf{z}^{*}$ & $\mathbf{t}$ \\
head & 9.723 & 7.161 & 20.000 & 0.476 \\
neck & 6.649 & 6.649 & 10.000 & 0.476 \\
thorax & 10.235 & 15.359 & 40.000 & 0.476 \\
pelvis & 10.235 & 18.433 & 20.000 & 0.476 \\
thigh (ea) & 7.673 & 7.673 & 40.000 & 0.476 \\
leg (ea) & 6.136 & 6.136 & 40.000 & 0.476 \\
arm (ea) & 5.112 & 5.112 & 60.000 & 0.476
\end{tabular}

$\%$ difference in fill volume $=10 \%$

\begin{tabular}{lrrcc} 
bottle & $\mathrm{a}^{*}$ & \multicolumn{1}{c}{$\mathrm{b}^{*}$} & $\mathrm{z}^{*}$ & $\mathrm{t}$ \\
head & 9.940 & 7.318 & 20.000 & 0.476 \\
neck & 6.794 & 6.794 & 10.000 & 0.476 \\
thorax & 10.465 & 15.709 & 40.000 & 0.476 \\
pelvis & 10.465 & 18.855 & 20.000 & 0.476 \\
thigh (ea) & 7.843 & 7.843 & 40.000 & 0.476 \\
leg (ea) & 6.270 & 6.270 & 40.000 & 0.476 \\
arm (ea) & 5.221 & 5.221 & 60.000 & 0.476
\end{tabular}

$\%$ difference in fill volume $=20 \%$

$\begin{array}{lrrcc}\text { bottle } & \mathrm{a}^{*} & \mathrm{~b}^{*} & \mathrm{z}^{*} & \mathrm{t} \\ \text { head } & 10.361 & 7.623 & 20.000 & 0.476 \\ \text { neck } & 7.075 & 7.075 & 10.000 & 0.476 \\ \text { thorax } & 10.909 & 16.386 & 40.000 & 0.476 \\ \text { pelvis } & 10.909 & 19.673 & 20.000 & 0.476 \\ \text { thigh (ea) } & 8.170 & 8.170 & 40.000 & 0.476 \\ \text { leg (ea) } & 6.527 & 6.527 & 40.000 & 0.476 \\ \text { arm (ea) } & 5.432 & 5.432 & 60.000 & 0.476\end{array}$


Experiment \#2B

Vary the fill volume of the phantom; vary the height proportionately.

$\%$ difference in fill volume $=-20 \%$

\begin{tabular}{lrrrr} 
bottle & $\mathrm{a}^{*}$ & \multicolumn{1}{c}{$\mathrm{b}^{*}$} & $\mathrm{z}^{*}$ & $\mathrm{t}$ \\
head & $\mathbf{8 . 8 5 3}$ & 6.532 & 18.635 & 0.476 \\
neck & 6.068 & 6.068 & 9.351 & 0.476 \\
thorax & 9.317 & 13.959 & 37.201 & 0.476 \\
pelvis & 9.317 & 16.744 & 18.635 & 0.476 \\
thigh (ea) & 6.997 & 6.997 & 37.201 & 0.476 \\
leg (ea) & 5.604 & 5.604 & 37.201 & 0.476 \\
arm (ea) & 4.676 & 4.676 & 55.767 & 0.476
\end{tabular}

$\%$ difference in fill volume $=-10 \%$

\begin{tabular}{lrrrr} 
bottle & $\mathrm{a}^{*}$ & \multicolumn{1}{c}{$\mathbf{b}^{*}$} & $\mathbf{z}^{*}$ & $\mathbf{t}$ \\
head & 9.189 & 6.775 & 19.343 & 0.476 \\
neck & 6.292 & 6.292 & 9.688 & 0.476 \\
thorax & 9.671 & 14.499 & 38.652 & 0.476 \\
pelvis & 9.671 & 17.395 & 19.343 & 0.476 \\
thigh (ea) & 7.258 & 7.258 & 38.652 & 0.476 \\
leg (ea) & 5.809 & 5.809 & 38.652 & 0.476 \\
arm (ea) & 4.844 & 4.844 & 57.962 & 0.476
\end{tabular}

$\%$ difference in fill volume $=-5 \%$

\begin{tabular}{lrrrr} 
bottle & $\mathrm{a}^{*}$ & \multicolumn{1}{c}{$\mathrm{b}^{*}$} & \multicolumn{1}{c}{$\mathrm{z}^{*}$} & $\mathrm{t}$ \\
head & 9.347 & 6.889 & 19.677 & 0.476 \\
neck & 6.398 & 6.398 & 9.847 & 0.476 \\
thorax & 9.839 & 14.754 & 39.338 & 0.476 \\
pelvis & 9.839 & 17.703 & 19.677 & 0.476 \\
thigh (ea) & 7.381 & 7.381 & 39.338 & 0.476 \\
leg (ea) & 5.906 & 5.906 & 39.338 & 0.476 \\
arm (ea) & 4.923 & 4.923 & 58.999 & 0.476
\end{tabular}

All distances are reported in $\mathrm{cm}$. Unless otherwise specified, $\mathrm{t}=\mathrm{t}^{*}$. 
Experiment \#2B (cont.)

Vary the fill volume of the phantom; vary the height proportionately.

$\%$ difference in fill volume $=5 \%$

\begin{tabular}{lrrrc} 
bottle & $\mathrm{a}^{*}$ & \multicolumn{1}{c}{$\mathrm{b}^{*}$} & $\mathrm{z}^{*}$ & $\mathrm{t}$ \\
head & 9.648 & 7.107 & 20.312 & 0.476 \\
neck & 6.599 & 6.599 & 10.148 & 0.476 \\
thorax & 10.156 & 15.238 & 40.640 & 0.476 \\
pelvis & 10.156 & 18.287 & 20.312 & 0.476 \\
thigh (ea) & 7.615 & 7.615 & 40.640 & 0.476 \\
leg (ea) & 6.091 & 6.091 & 40.640 & 0.476 \\
arm (ea) & 5.074 & 5.074 & 60.968 & 0.476
\end{tabular}

$\%$ difference in fill volume $=10 \%$

\begin{tabular}{lrrcc} 
bottle & $\mathrm{a}^{*}$ & \multicolumn{1}{c}{$\mathrm{b}^{*}$} & $\mathrm{z}^{*}$ & $\mathrm{t}$ \\
head & 9.791 & 7.211 & 20.615 & 0.476 \\
neck & 6.694 & 6.694 & 10.292 & 0.476 \\
thorax & 10.307 & 15.469 & 41.260 & 0.476 \\
pelvis & 10.307 & 18.566 & 20.615 & 0.476 \\
thigh (ea) & 7.727 & 7.727 & 41.260 & 0.476 \\
leg (ea) & 6.178 & 6.178 & 41.260 & 0.476 \\
arm (ea) & 5.146 & 5.146 & 61.906 & 0.476
\end{tabular}

$\%$ difference in fill volume $=20 \%$

$\begin{array}{lrrcc}\text { bottle } & \mathrm{a}^{*} & \mathrm{~b}^{*} & \mathbf{z}^{*} & \mathrm{t} \\ \text { head } & 10.065 & 7.409 & 21.194 & 0.476 \\ \text { neck } & 6.877 & 6.877 & 10.567 & 0.476 \\ \text { thorax } & 10.597 & 15.910 & 42.447 & 0.476 \\ \text { pelvis } & 10.597 & 19.098 & 21.194 & 0.476 \\ \text { thigh (ea) } & 7.940 & 7.940 & 42.447 & 0.476 \\ \text { leg (ea) } & 6.346 & 6.346 & 42.447 & 0.476 \\ \text { arm (ea) } & 5.283 & 5.283 & 63.700 & 0.476\end{array}$


Experiment \#3A

Vary the density of the polyurethane fill material.

BOMAB phantom dimensions are those given in Table 1 for the average adult male human body.

$\%$ difference in density of polyurethane fill material $\quad \mu / \mathrm{p}\left(\mathrm{cm}^{2} \mathrm{~g}^{-1}\right)$

$\begin{array}{rr}0 \% \text { (standard density) } & 1.09 \\ -20 \% & 0.87 \\ -10 \% & 0.98 \\ -5 \% & 1.04 \\ 5 \% & 1.14 \\ 10 \% & 1.12 \\ 20 \% & 1.31\end{array}$

Experiment \#3B

Vary the density of the water fill material.

BOMAB phantom dimensions are those given in Table 1 for the average adult male human body.

$\%$ difference in density of water fill material

$\begin{array}{lc}\text { sity of water fill material } & \mu / \rho\left(\mathrm{cm}^{2} \mathrm{~g}^{-1}\right) \\ 0 \% \text { (standard density) } & 1.00 \\ -20 \% & 0.80 \\ -10 \% & 0.90 \\ -5 \% & 0.95 \\ 5 \% & 1.05 \\ 10 \% & 1.10 \\ 20 \% & 1.20\end{array}$




\section{Experiment \#4}

Vary the wall thickness of the phantom.

$\%$ difference in wall thickness $=-20 \%$

\begin{tabular}{lrrrcc} 
bottle & $\mathrm{a}^{*}$ & \multicolumn{1}{c}{$\mathrm{b}^{*}$} & \multicolumn{1}{c}{$\mathbf{z}^{*}$} & $\mathbf{t}$ & $\mathrm{t}^{*}$ \\
head & 9.405 & 6.905 & 19.810 & 0.476 & 0.381 \\
neck & 6.405 & 6.405 & 9.810 & 0.476 & 0.381 \\
thorax & 9.905 & 14.905 & 39.810 & 0.476 & 0.381 \\
pelvis & 9.905 & 17.905 & 19.810 & 0.476 & 0.381 \\
thigh (ea) & 7.405 & 7.405 & 39.810 & 0.476 & 0.381 \\
leg (ea) & 5.905 & 5.905 & 39.810 & 0.476 & 0.381 \\
arm (ea) & 4.905 & 4.905 & 59.810 & 0.476 & 0.381
\end{tabular}

$\%$ difference in wall thickness $=-10 \%$

\begin{tabular}{lrrrcc} 
bottle & $\mathrm{a}^{*}$ & $\mathrm{~b}^{*}$ & \multicolumn{1}{c}{$\mathrm{z}^{*}$} & $\mathrm{t}$ & $\mathrm{t}^{*}$ \\
head & 9.452 & 6.952 & 19.905 & 0.476 & 0.428 \\
neck & 6.452 & 6.452 & 9.905 & 0.476 & 0.428 \\
thorax & 9.952 & 14.952 & 39.905 & 0.476 & 0.428 \\
pelvis & 9.952 & 17.952 & 19.905 & 0.476 & 0.428 \\
thigh (ea) & 7.452 & 7.452 & 39.905 & 0.476 & 0.428 \\
leg (ea) & 5.952 & 5.952 & 39.905 & 0.476 & 0.428 \\
arm (ea) & 4.952 & 4.952 & 59.905 & 0.476 & 0.428
\end{tabular}

$\%$ difference in wall thickness $=-5 \%$

\begin{tabular}{lrrrrc} 
bottlc & $\mathrm{a}^{*}$ & \multicolumn{1}{c}{$\mathrm{b}^{*}$} & \multicolumn{1}{c}{$\mathbf{z}^{*}$} & $\mathrm{t}$ & $\mathrm{t}^{*}$ \\
head & 9.476 & 6.976 & 19.952 & 0.476 & 0.452 \\
neck & 6.476 & 6.476 & 9.952 & 0.476 & 0.452 \\
thorax & 9.976 & 14.976 & 39.952 & 0.476 & 0.452 \\
pelvis & 9.976 & 17.976 & 19.952 & 0.476 & 0.452 \\
thigh (ea) & 7.476 & 7.476 & 39.952 & 0.476 & 0.452 \\
leg (ea) & 5.976 & 5.976 & 39.952 & 0.476 & 0.452 \\
arm (ea) & 4.976 & 4.976 & 59.952 & 0.476 & 0.452
\end{tabular}

All distances are reported in $\mathrm{cm}$. 
Experiment \#4 (cont.)

Vary the wall thickness of the phantom.

$\%$ difference in wall thickness $=5 \%$

\begin{tabular}{lrrccc} 
bottle & \multicolumn{1}{c}{$\mathrm{a}^{*}$} & $\mathrm{~b}^{*}$ & $\mathrm{z}^{*}$ & $\mathrm{t}$ & $\mathrm{t}^{*}$ \\
head & 9.524 & 7.024 & 20.048 & 0.476 & 0.500 \\
neck & 6.524 & 6.524 & 10.048 & 0.476 & 0.500 \\
thorax & 10.024 & 15.024 & 40.048 & 0.476 & 0.500 \\
pelvis & 10.024 & 18.024 & 20.048 & 0.476 & 0.500 \\
thigh (ea) & 7.524 & 7.524 & 40.048 & 0.476 & 0.500 \\
leg (ea) & 6.024 & 6.024 & 40.048 & 0.476 & 0.500 \\
arm (ea) & 5.024 & 5.024 & 60.048 & 0.476 & 0.500
\end{tabular}

$\%$ difference in wall thickness $=10 \%$

\begin{tabular}{lrrccc} 
bottle & \multicolumn{1}{c}{$\mathbf{a}^{*}$} & $\mathbf{b}^{*}$ & $\mathbf{z}^{*}$ & $\mathbf{t}$ & $\mathrm{t}^{*}$ \\
head & 9.548 & 7.048 & 20.095 & 0.476 & 0.524 \\
neck & 6.548 & 6.548 & 10.095 & 0.476 & 0.524 \\
thorax & 10.048 & 15.048 & 40.095 & 0.476 & 0.524 \\
pelvis & 10.048 & 18.048 & 20.095 & 0.476 & 0.524 \\
thigh (ea) & 7.548 & 7.548 & 40.095 & 0.476 & 0.524 \\
leg (ea) & 6.048 & 6.048 & 40.095 & 0.476 & 0.524 \\
arm (ea) & 5.048 & 5.048 & 60.095 & 0.476 & 0.524
\end{tabular}

$\%$ difference in wall thickness $=20 \%$

$\begin{array}{lrrccc}\text { bottle } & \mathrm{a}^{*} & \mathrm{~b}^{*} & \mathrm{z}^{*} & \mathrm{t} & \mathrm{t}^{*} \\ \text { head } & 9.595 & 7.095 & 20.190 & 0.476 & 0.571 \\ \text { neck } & 6.595 & 6.595 & 10.190 & 0.476 & 0.571 \\ \text { thorax } & 10.095 & 15.095 & 40.190 & 0.476 & 0.571 \\ \text { pelvis } & 10.095 & 18.095 & 20.190 & 0.476 & 0.571 \\ \text { thigh (ea) } & 7.595 & 7.595 & 40.190 & 0.476 & 0.571 \\ \text { leg (ea) } & 6.095 & 6.095 & 40.190 & 0.476 & 0.571 \\ \text { arm (ea) } & 5.095 & 5.095 & 60.190 & 0.476 & 0.571\end{array}$


Experiment \#4 (cont.)

Vary the wall thickness of the phantom.

Wall thickness is defined as $10 \mathrm{~mm}$.

$\begin{array}{lrrccc}\text { bottle } & \mathrm{a}^{*} & \mathrm{~b}^{*} & \mathrm{z}^{*} & \mathrm{t} & \mathrm{t}^{*} \\ \text { head } & 10.024 & 7.524 & 21.048 & 0.476 & 1.000 \\ \text { neck } & 7.024 & 7.024 & 11.048 & 0.476 & 1.000 \\ \text { thorax } & 10.524 & 15.524 & 41.048 & 0.476 & 1.000 \\ \text { pelvis } & 10.524 & \mathbf{1 8 . 5 2 4} & 2.1 .048 & 0.476 & 1.000 \\ \text { thigh (ea) } & \mathbf{8 . 0 2 4} & \mathbf{8 . 0 2 4} & 41.048 & 0.476 & 1.000 \\ \text { leg (ea) } & 6.524 & 6.524 & 41.048 & 0.476 & 1.000 \\ \text { arm (ea) } & 5.524 & 5.524 & 61.048 & 0.476 & 1.000\end{array}$

Experiment \#5A

Vary the source concentration of the thorax.

BOMAB phantom dimensions are those given in Table 1 for the average adult male human body.

$\%$ difference in source concentration of polyurethane fill material within the thorax

$0 \%$ (standard concentration
throughout phantom)
$-20 \%$
$-10 \%$
$-5 \%$
$5 \%$
$10 \%$
$20 \%$

Normalized source photon concentration (source photons $\mathrm{cm}^{-3}$ ) 1.00

0.80

0.90

0.95

1.05

1.10

1.20 
Experiment \#5B

Vary the source concentration of the pelvis.

BOMAB phantom dimensions are those given in Table 1 for the average adult male human body.

$\%$ difference in source concentration of polyurethane fill material within the pelvis $0 \%$ (standard concentration throughout phantom) $-20 \%$

$-10 \%$

$-5 \%$

$5 \%$

$10 \%$

$20 \%$
Normalized source photon concentration (source photons $\mathrm{cm}^{-3}$ )

1.00

0.80

0.90

0.95

1.05

1.10

1.20

Experiment \#5C

Vary the source concentration of the thorax, pelvis, and arms.

BOMAB phantom dimensions are those given in Table 1 for the average adult male human body.

$\%$ difference in source concentration of polyurethane fill material within the thorax pelvis, and arms $0 \%$ (standard concentration
throughout phantom)

Normalized source photon concentration (source photons $\mathrm{cm}^{-3}$ )

1.00

$-20 \%$
$-10 \%$
$-5 \%$
$5 \%$
$10 \%$
$20 \%$

0.80

0.90

0.95

1.05

1.10

1.20 
Experiment \#1

Vary the height of the phantom.

Relative BOMAB surface current (source energy photons/source photon)

$\begin{array}{ccccccc}\text { \% change } & 0.200 \mathrm{MeV} & 3 \sigma & 0.662 \mathrm{MeV} & 3 \sigma & 1.460 \mathrm{MeV} & 3 \sigma \\ -20 \% & 0.331710 & 0.004478 & 0.453070 & 0.004757 & 0.557120 & 0.004680 \\ -10 \% & 0.342120 & 0.004516 & 0.464040 & 0.004733 & 0.567740 & 0.004769 \\ -5 \% & 0.347160 & 0.004478 & 0.469450 & 0.004788 & 0.572730 & 0.004639 \\ 0 \% & 0.352097 & 0.001479 & 0.473819 & 0.001564 & 0.577123 & 0.001558 \\ 5 \% & 0.357260 & 0.004501 & 0.479270 & 0.004745 & 0.582470 & 0.004718 \\ 10 \% & 0.361840 & 0.004559 & 0.484300 & 0.004795 & 0.587490 & 0.004582 \\ 20 \% & 0.370410 & 0.004556 & 0.493160 & 0.004734 & 0.596460 & 0.004652\end{array}$

Relative PNL in vivo system detector current

(source energy photons incident upon detectors/source photon)

$\begin{array}{ccccccc}\text { \% change } & 0.200 \mathrm{MeV} & 3 \sigma & 0.662 \mathrm{MeV} & 3 \sigma & 1.460 \mathrm{MeV} & 3 \sigma \\ -20 \% & 0.043379 & 0.000612 & 0.060375 & 0.000706 & 0.075330 & 0.000791 \\ -10 \% & 0.047599 & 0.000643 & 0.065636 & 0.000748 & 0.081459 & 0.000831 \\ -5 \% & 0.047973 & 0.000648 & 0.065900 & 0.000751 & 0.081506 & 0.000831 \\ 0 \% & 0.048046 & 0.000202 & 0.065956 & 0.000237 & 0.081499 & 0.000269 \\ 5 \% & 0.048361 & 0.000638 & 0.066000 & 0.000752 & 0.081492 & 0.000831 \\ 10 \% & 0.048355 & 0.000638 & 0.065939 & 0.000752 & 0.081114 & 0.000827 \\ 20 \% & 0.046934 & 0.000634 & 0.063681 & 0.000726 & 0.077889 & 0.000794\end{array}$

Relative PNL 29-cm NaI detector current (source energy photons incident upon 29-cm NaI detector/source photon)

$\begin{array}{rcccccc}\text { \% change } & 0.200 \mathrm{MeV} & 3 \sigma & 0.662 \mathrm{MeV} & 3 \sigma & 1.460 \mathrm{MeV} & 3 \sigma \\ -20 \% & 0.013213 & 0.000341 & 0.018628 & 0.000408 & 0.023501 & 0.000451 \\ -10 \% & 0.016134 & 0.000378 & 0.022721 & 0.000450 & 0.028653 & 0.000499 \\ -5 \% & 0.016549 & 0.000382 & 0.023253 & 0.000453 & 0.029302 & 0.000510 \\ 0 \% & 0.016479 & 0.000119 & 0.023265 & 0.000140 & 0.029343 & 0.000158 \\ 5 \% & 0.016490 & 0.000381 & 0.023082 & 0.000450 & 0.029140 & 0.000507 \\ 10 \% & 0.016247 & 0.000380 & 0.022818 & 0.000445 & 0.028652 & 0.000499 \\ 20 \% & 0.015639 & 0.000371 & 0.021919 & 0.000441 & 0.027361 & 0.000492\end{array}$


Experiment \#2A

Vary the fill volume of the phantom; hold the height constant.

Relative BOMAB surface current

(source energy photons/source photon)

$\begin{array}{ccccccc}\text { \% change } & 0.200 \mathrm{MeV} & 3 \sigma & 0.662 \mathrm{MeV} & 3 \sigma & 1.460 \mathrm{MeV} & 3 \sigma \\ -20 \% & 0.377040 & 0.004638 & 0.500300 & 0.004803 & 0.602480 & 0.004699 \\ -10 \% & 0.364050 & 0.004587 & 0.486730 & 0.004673 & 0.589490 & 0.004598 \\ -5 \% & 0.358170 & 0.004513 & 0.480170 & 0.004754 & 0.583740 & 0.004728 \\ 0 \% & 0.352097 & 0.001479 & 0.473819 & 0.001564 & 0.577123 & 0.001558 \\ 5 \% & 0.346710 & 0.004473 & 0.468980 & 0.004784 & 0.572360 & 0.004636 \\ 10 \% & 0.341580 & 0.004509 & 0.463450 & 0.004727 & 0.566920 & 0.004762 \\ 20 \% & 0.332540 & 0.004489 & 0.453400 & 0.004761 & 0.556990 & 0.004679\end{array}$

Relative PNL in vivo system detector current

(source energy photons incident upon detectors/source photon)

$\begin{array}{ccccccc}\text { \% change } & 0.200 \mathrm{MeV} & 3 \sigma & 0.662 \mathrm{MeV} & 3 \sigma & 1.460 \mathrm{MeV} & 3 \sigma \\ -20 \% & 0.056127 & 0.000690 & 0.075879 & 0.000797 & 0.092436 & 0.000860 \\ -10 \% & 0.051804 & 0.000668 & 0.070558 & 0.000762 & 0.086577 & 0.000831 \\ -5 \% & 0.049872 & 0.000658 & 0.068108 & 0.000756 & 0.083960 & 0.000831 \\ 0 \% & 0.048046 & 0.000202 & 0.065956 & 0.000237 & 0.081499 & 0.000269 \\ 5 \% & 0.046442 & 0.000627 & 0.063876 & 0.000728 & 0.079186 & 0.000808 \\ 10 \% & 0.044933 & 0.000620 & 0.062017 & 0.000726 & 0.077133 & 0.000810 \\ 20 \% & 0.042106 & 0.000606 & 0.058559 & 0.000703 & 0.073180 & 0.000790\end{array}$

Relative PNL 29-cm NaI detector current

(source energy photons incident upon $29-\mathrm{cm} \mathrm{NaI}$ detector/source photon)

$\begin{array}{rcccccc}\text { \% change } & 0.200 \mathrm{MeV} & 3 \sigma & 0.662 \mathrm{MeV} & 3 \sigma & 1.460 \mathrm{MeV} & 3 \sigma \\ -20 \% & 0.019359 & 0.000412 & 0.026880 & 0.000484 & 0.033354 & 0.000540 \\ -10 \% & 0.017857 & 0.000396 & 0.024956 & 0.000472 & 0.031238 & 0.000525 \\ -5 \% & 0.017178 & 0.000392 & 0.024086 & 0.000462 & 0.030290 & 0.000518 \\ 0 \% & 0.016479 & 0.000119 & 0.023265 & 0.000140 & 0.029343 & 0.000158 \\ 5 \% & 0.015961 & 0.000378 & 0.022572 & 0.000447 & 0.028488 & 0.000496 \\ 10 \% & 0.015430 & 0.000370 & 0.021902 & 0.000440 & 0.027754 & 0.000491 \\ 20 \% & 0.014417 & 0.000359 & 0.020644 & 0.000427 & 0.026310 & 0.000481\end{array}$


Experiment \#2B

Vary the fill volume of the phantom; vary the height proportionately.

Relative BOMAB surface current

(source energy photons/source photon)

$\begin{array}{ccccccc}\% \text { change } & 0.200 \mathrm{MeV} & 3 \sigma & 0.662 \mathrm{MeV} & 3 \sigma & 1.460 \mathrm{MeV} & 3 \sigma \\ -20 \% & 0.369420 & 0.004544 & 0.492540 & 0.004728 & 0.595670 & 0.004646 \\ -10 \% & 0.360530 & 0.004543 & 0.482970 & 0.004781 & 0.586400 & 0.004750 \\ -5 \% & 0.356210 & 0.004595 & 0.478590 & 0.004738 & 0.581810 & 0.004713 \\ 0 \% & 0.352097 & 0.001479 & 0.473819 & 0.001564 & 0.577123 & 0.001558 \\ 5 \% & 0.348170 & 0.004491 & 0.470490 & 0.004799 & 0.574100 & 0.004650 \\ 10 \% & 0.344580 & 0.004548 & 0.466560 & 0.004759 & 0.570460 & 0.004621 \\ 20 \% & 0.337880 & 0.004460 & 0.458930 & 0.004681 & 0.562780 & 0.004727\end{array}$

Relative PNL in vivo system detector current

(source energy photons incident upon detectors/source photon)

$\begin{array}{ccccccc}\text { \% change } & 0.200 \mathrm{MeV} & 3 \sigma & 0.662 \mathrm{MeV} & 3 \sigma & 1.460 \mathrm{MeV} & 3 \mathrm{c} \\ -20 \% & 0.056031 & 0.000689 & 0.075831 & 0.000796 & 0.092626 & 0.000861 \\ -10 \% & 0.051614 & 0.000666 & 0.070407 & 0.000760 & 0.086470 & 0.000856 \\ -5 \% & 0.049755 & 0.000657 & 0.068012 & 0.000755 & 0.083811 & 0.000830 \\ 0 \% & 0.048046 & 0.000202 & 0.065956 & 0.000237 & 0.081499 & 0.000269 \\ 5 \% & 0.046558 & 0.000629 & 0.063933 & 0.000729 & 0.079211 & 0.000808 \\ 10 \% & 0.045147 & 0.000623 & 0.062197 & 0.000728 & 0.077182 & 0.000810 \\ 20 \% & 0.042299 & 0.000609 & 0.058571 & 0.000703 & 0.073020 & 0.000789\end{array}$

Relative PNL 29-cm NaI detector current (source energy photons incident upon $29-\mathrm{cm} \mathrm{Nal}$ detector/source photon)

$\begin{array}{ccccccc}\text { \% change } & 0.200 \mathrm{MeV} & 3 \sigma & 0.662 \mathrm{MeV} & 3 \sigma & 1.460 \mathrm{MeV} & 3 \sigma \\ -20 \% & 0.019270 & 0.000410 & 0.026730 & 0.000481 & 0.033237 & 0.000538 \\ -10 \% & 0.017894 & 0.000397 & 0.025033 & 0.000466 & 0.031294 & 0.000526 \\ -5 \% & 0.017158 & 0.000391 & 0.024102 & 0.000463 & 0.030280 & 0.000518 \\ 0 \% & 0.016479 & 0.000119 & 0.023265 & 0.000140 & 0.029343 & 0.000158 \\ 5 \% & 0.015917 & 0.000377 & 0.022460 & 0.000445 & 0.028415 & 0.000494 \\ 10 \% & 0.015389 & 0.000369 & 0.021794 & 0.000438 & 0.027625 & 0.000489 \\ 20 \% & 0.014267 & 0.000355 & 0.020366 & 0.000422 & 0.025969 & 0.000475\end{array}$


Experiment \#3A

Vary the density of the polyurethane fill material.

Relative BOMAB surface current

(source energy photons/source photon)

$\begin{array}{ccccccc}\text { \% change } & 0.200 \mathrm{MeV} & 3 \sigma & 0.662 \mathrm{MeV} & 3 \sigma & 1.460 \mathrm{MeV} & 3 \sigma \\ -20 \% & 0.405090 & 0.004618 & 0.528440 & 0.004756 & 0.629370 & 0.004531 \\ -10 \% & 0.376490 & 0.004631 & 0.500570 & 0.004805 & 0.602410 & 0.004699 \\ -5 \% & 0.363250 & 0.004577 & 0.485740 & 0.004809 & 0.589150 & 0.004595 \\ 0 \% & 0.352097 & 0.001479 & 0.473819 & 0.001564 & 0.577123 & 0.001558 \\ 5 \% & 0.341730 & 0.004511 & 0.463510 & 0.004728 & 0.567010 & 0.004763 \\ 10 \% & 0.330300 & 0.004459 & 0.450760 & 0.004733 & 0.554580 & 0.004658 \\ 20 \% & 0.310270 & 0.004375 & 0.428800 & 0.004631 & 0.533150 & 0.004798\end{array}$

Relative PNL in vivo system detector current (source energy photons incident upon detectors/source photon)

$\begin{array}{ccccccc}\text { \% change } & 0.200 \mathrm{MeV} & 3 \sigma & 0.662 \mathrm{MeV} & 3 \sigma & 1.460 \mathrm{MeV} & 3 \sigma \\ -20 \% & 0.055749 & 0.000686 & 0.074046 & 0.000777 & 0.089187 & 0.000856 \\ -10 \% & 0.051629 & 0.000666 & 0.069800 & 0.000775 & 0.085217 & 0.000844 \\ -5 \% & 0.049595 & 0.000655 & 0.067616 & 0.000751 & 0.083090 & 0.000823 \\ 0 \% & 0.048046 & 0.000202 & 0.065956 & 0.000237 & 0.081499 & 0.000269 \\ 5 \% & 0.046614 & 0.000629 & 0.064300 & 0.000733 & 0.079872 & 0.000815 \\ 10 \% & 0.044918 & 0.000620 & 0.062452 & 0.000731 & 0.078076 & 0.000796 \\ 20 \% & 0.042027 & 0.000605 & 0.059345 & 0.000712 & 0.074852 & 0.000786\end{array}$

Relative PNL 29-cm NaI detector current

(source energy photons incident upon 29-cm Nal detector/source photon)

$\begin{array}{ccccccc}\% \text { change } & 0.200 \mathrm{MeV} & 3 \sigma & 0.662 \mathrm{MeV} & 3 \sigma & 1.460 \mathrm{MeV} & 3 \sigma \\ -20 \% & 0.019360 & 0.000412 & 0.026474 & 0.000484 & 0.032446 & 0.000535 \\ -10 \% & 0.017834 & 0.000396 & 0.024852 & 0.000470 & 0.030894 & 0.000519 \\ -5 \% & 0.017120 & 0.000390 & 0.023997 & 0.000461 & 0.030035 & 0.000514 \\ 0 \% & 0.016479 & 0.000119 & 0.023265 & 0.000140 & 0.029343 & 0.000158 \\ 5 \% & 0.015996 & 0.000374 & 0.022718 & 0.000450 & 0.028789 & 0.000501 \\ 10 \% & 0.015388 & 0.000369 & 0.022026 & 0.000443 & 0.028086 & 0.000497 \\ 20 \% & 0.014343 & 0.000357 & 0.020814 & 0.000431 & 0.026841 & 0.000483\end{array}$


Experiment \#3B

Vary the density of the water fill material.

Relative BOMAB surface current

(source energy photons/source photon)

$\begin{array}{ccccccc}\% \text { change } & 0.200 \mathrm{MeV} & 3 \sigma & 0.662 \mathrm{MeV} & 3 \sigma & 1.460 \mathrm{MeV} & 3 \sigma \\ -20 \% & 0.419610 & 0.004658 & 0.543230 & 0.004726 & 0.642230 & 0.004624 \\ -10 \% & 0.391710 & 0.004583 & 0.515570 & 0.004795 & 0.616890 & 0.004627 \\ -5 \% & 0.378870 & 0.004546 & 0.502640 & 0.004675 & 0.604540 & 0.004715 \\ 0 \% & 0.366925 & 0.001431 & 0.489404 & 0.001468 & 0.591796 & 0.001420 \\ 5 \% & 0.355840 & 0.004590 & 0.478030 & 0.004732 & 0.581210 & 0.004708 \\ 10 \% & 0.344910 & 0.004553 & 0.466760 & 0.004761 & 0.570690 & 0.004623 \\ 20 \% & 0.325410 & 0.004491 & 0.445610 & 0.004679 & 0.549440 & 0.004780\end{array}$

Relative PNL in vivo system detector current

(source energy photons incident upon detectors/source photon)

$\begin{array}{ccccccc}\% \text { change } & 0.200 \mathrm{MeV} & 3 \sigma & 0.662 \mathrm{MeV} & 3 \sigma & 1.460 \mathrm{MeV} & 3 \sigma \\ -20 \% & 0.057917 & 0.000695 & 0.076258 & 0.000801 & 0.091144 & 0.000875 \\ -10 \% & 0.053768 & 0.000677 & 0.072109 & 0.000779 & 0.087347 & 0.000839 \\ -5 \% & 0.051941 & 0.000670 & 0.070127 & 0.000757 & 0.085506 & 0.000847 \\ 0 \% & 0.050217 & 0.000211 & 0.068282 & 0.000246 & 0.083750 & 0.000251 \\ 5 \% & 0.048571 & 0.000641 & 0.066437 & 0.000737 & 0.081977 & 0.000812 \\ 10 \% & 0.047052 & 0.000635 & 0.064806 & 0.000739 & 0.080355 & 0.000820 \\ 20 \% & 0.044188 & 0.000623 & 0.061690 & 0.000722 & 0.077261 & 0.000811\end{array}$

Relative PNL 29-cm Nal detector current (source energy photons incident upon 29-cm। NaI detector/source photon)

$\begin{array}{ccccccc}\text { \% change } & 0.200 \mathrm{MeV} & 3 \sigma & 0.662 \mathrm{MeV} & 3 \sigma & 1.460 \mathrm{MeV} & 3 \sigma \\ -20 \% & 0.020197 & 0.000424 & 0.027326 & 0.000492 & 0.033253 & 0.000539 \\ -10 \% & 0.018613 & 0.000408 & 0.025739 & 0.000479 & 0.031720 & 0.000523 \\ -5 \% & 0.017940 & 0.000398 & 0.024992 & 0.000465 & 0.030994 & 0.000521 \\ 0 \% & 0.017281 & 0.000124 & 0.024152 & 0.000145 & 0.030242 & 0.000163 \\ 5 \% & 0.016734 & 0.000387 & 0.023541 & 0.000452 & 0.029600 & 0.000506 \\ 10 \% & 0.016166 & 0.000378 & 0.022914 & 0.000447 & 0.028946 & 0.000504 \\ 20 \% & 0.015123 & 0.000367 & 0.021728 & 0.000437 & 0.027777 & 0.000492\end{array}$


Experiment \#4

Vary the wall thickness of the phantom.

Relative BOMAB surface current

(source energy photons/source photon)

$\begin{array}{ccccccc}\% \text { change } & 0.200 \mathrm{MeV} & 3 \sigma & 0.662 \mathrm{MeV} & 3 \sigma & 1.460 \mathrm{MeV} & 3 \sigma \\ -20 \% & 0.359650 & 0.004532 & 0.480910 & 0.004761 & 0.583110 & 0.004723 \\ -10 \% & 0.356110 & 0.004594 & 0.477700 & 0.004729 & 0.580520 & 0.004702 \\ -5 \% & 0.354360 & 0.004571 & 0.476250 & 0.004715 & 0.579340 & 0.004693 \\ 0 \% & 0.352097 & 0.001479 & 0.473819 & 0.001564 & 0.577123 & 0.001558 \\ 5 \% & 0.351120 & 0.004529 & 0.473050 & 0.004683 & 0.576540 & 0.004670 \\ 10 \% & 0.349290 & 0.004506 & 0.471520 & 0.004668 & 0.575220 & 0.004659 \\ 20 \% & 0.346220 & 0.004466 & 0.468450 & 0.004778 & 0.572560 & 0.004638 \\ 110 \% & 0.318290 & 0.004392 & 0.443230 & 0.004654 & 0.550810 & 0.004792\end{array}$

Relative PNL in vivo system detector current

(source energy photons incident upon detectors/source photon)

$\begin{array}{rcccccc}\text { \% change } & 0.200 \mathrm{MeV} & 3 \sigma & 0.662 \mathrm{MeV} & 3 \sigma & 1.460 \mathrm{MeV} & 3 \sigma \\ -20 \% & 0.049421 & 0.000652 & 0.067249 & 0.000746 & 0.082869 & 0.000820 \\ -10 \% & 0.048781 & 0.000644 & 0.066606 & 0.000739 & 0.082211 & 0.000814 \\ -5 \% & 0.048429 & 0.000639 & 0.066214 & 0.000755 & 0.081836 & 0.000810 \\ 0 \% & 0.048046 & 0.000202 & 0.065956 & 0.000237 & 0.081499 & 0.000269 \\ 5 \% & 0.047766 & 0.000645 & 0.065555 & 0.000747 & 0.081141 & 0.000828 \\ 10 \% & 0.047413 & 0.000640 & 0.065203 & 0.000743 & 0.080785 & 0.000824 \\ 20 \% & 0.046788 & 0.000632 & 0.064493 & 0.000735 & 0.080125 & 0.000817 \\ 110 \% & 0.041503 & 0.000598 & 0.058934 & 0.000707 & 0.074353 & 0.000781\end{array}$

Relative PNL 29-cm NaI detector current (source energy photons incident upon 29-cm NaI detector/source photon)

$\begin{array}{ccccccc}\text { \% change } & 0.200 \mathrm{MeV} & 3 \sigma & 0.662 \mathrm{MeV} & 3 \sigma & 1.460 \mathrm{MeV} & 3 \sigma \\ -20 \% & 0.017006 & 0.000388 & 0.023777 & 0.000457 & 0.029864 & 0.000511 \\ -10 \% & 0.016801 & 0.000383 & 0.023575 & 0.000453 & 0.029642 & 0.000507 \\ -5 \% & 0.016672 & 0.000385 & 0.023441 & 0.000457 & 0.029479 & 0.000504 \\ 0 \% & 0.016479 & 0.000119 & 0.023265 & 0.000140 & 0.029343 & 0.000158 \\ 5 \% & 0.016436 & 0.000380 & 0.023204 & 0.000452 & 0.029253 & 0.000509 \\ 10 \% & 0.016294 & 0.000381 & 0.023060 & 0.000450 & 0.029128 & 0.000507 \\ 20 \% & 0.016093 & 0.000377 & 0.022775 & 0.000451 & 0.028828 & 0.000502 \\ 110 \% & 0.014144 & 0.000352 & 0.020596 & 0.000426 & 0.026510 & 0.000485\end{array}$


Experiment \#5A

Vary the source concentration of the thorax.

Relative BOMAB surface current

(source energy photons/source photon)

$\begin{array}{ccccccc}\% \text { change } & 0.200 \mathrm{MeV} & 3 \sigma & 0.662 \mathrm{MeV} & 3 \sigma & 1.460 \mathrm{MeV} & 3 \sigma \\ -20 \% & 0.357380 & 0.004503 & 0.480200 & 0.004754 & 0.583000 & 0.004722 \\ -10 \% & 0.355030 & 0.004580 & 0.477580 & 0.004728 & 0.580570 & 0.004703 \\ -5 \% & 0.353830 & 0.004564 & 0.476130 & 0.004714 & 0.579420 & 0.004693 \\ 0 \% & 0.352097 & 0.001479 & 0.473819 & 0.001564 & 0.577123 & 0.001558 \\ 5 \% & 0.351340 & 0.004532 & 0.473270 & 0.004685 & 0.576320 & 0.004668 \\ 10 \% & 0.350090 & 0.004516 & 0.472220 & 0.004675 & 0.575110 & 0.004658 \\ 20 \% & 0.348150 & 0.004491 & 0.470250 & 0.004797 & 0.573220 & 0.004643\end{array}$

Relative PNL in vivo system detector current (source energy photons incident upon detectors/source photon)

$\begin{array}{ccccccc}\text { \% change } & 0.200 \mathrm{MeV} & 3 \sigma & 0.662 \mathrm{MeV} & 3 \sigma & 1.460 \mathrm{MeV} & 3 \sigma \\ -20 \% & 0.047672 & 0.000644 & 0.065265 & 0.000744 & 0.080503 & 0.000821 \\ -10 \% & 0.047914 & 0.000647 & 0.065664 & 0.000749 & 0.081031 & 0.000827 \\ -5 \% & 0.048092 & 0.000635 & 0.065909 & 0.000751 & 0.081376 & 0.000830 \\ 0 \% & 0.048046 & 0.000202 & 0.065956 & 0.000237 & 0.081499 & 0.000269 \\ 5 \% & 0.048113 & 0.000635 & 0.066022 & 0.000753 & 0.081658 & 0.000833 \\ 10 \% & 0.048276 & 0.000637 & 0.066311 & 0.000756 & 0.081994 & 0.000812 \\ 20 \% & 0.048555 & 0.000641 & 0.066761 & 0.000741 & 0.082573 & 0.000817\end{array}$

Relative PNL 29-cm NaI detector current (source energy photons incident upon $29-\mathrm{cm} \mathrm{NaI}$ detector/source photon)

$\begin{array}{ccccccc}\text { \% change } & 0.200 \mathrm{MeV} & 3 \sigma & 0.662 \mathrm{MeV} & 3 \sigma & 1.460 \mathrm{MeV} & 3 \sigma \\ -20 \% & 0.015361 & 0.000369 & 0.021679 & 0.000436 & 0.027329 & 0.000492 \\ -10 \% & 0.015993 & 0.000374 & 0.022548 & 0.000446 & 0.028380 & 0.000502 \\ -5 \% & 0.016321 & 0.000382 & 0.022996 & 0.000448 & 0.028934 & 0.000503 \\ 0 \% & 0.016479 & 0.000119 & 0.023265 & 0.000140 & 0.029343 & 0.000158 \\ 5 \% & 0.016828 & 0.000384 & 0.023718 & 0.000455 & 0.029863 & 0.000511 \\ 10 \% & 0.017109 & 0.000390 & 0.024144 & 0.000464 & 0.030365 & 0.000519 \\ 20 \% & 0.017655 & 0.000397 & 0.024909 & 0.000471 & 0.031346 & 0.000527\end{array}$


Experiment \#5B

Vary the source concentration of the pelvis.

Relative BOMAB surface current

(source energy photons/source photon)

$\begin{array}{ccccccc}\text { \% change } & 0.200 \mathrm{MeV} & 3 \sigma & 0.662 \mathrm{MeV} & 3 \sigma & 1.460 \mathrm{MeV} & 3 \sigma \\ -20 \% & 0.355090 & 0.004581 & 0.477550 & 0.004728 & 0.580600 & 0.004703 \\ -10 \% & 0.353930 & 0.004566 & 0.476060 & 0.004713 & 0.579200 & 0.004692 \\ -5 \% & 0.353270 & 0.004557 & 0.475420 & 0.004707 & 0.578660 & 0.004687 \\ 0 \% & 0.352097 & 0.001479 & 0.473819 & 0.001564 & 0.577123 & 0.001558 \\ 5 \% & 0.351860 & 0.004539 & 0.473870 & 0.004691 & 0.577200 & 0.004675 \\ 10 \% & 0.351200 & 0.004530 & 0.473270 & 0.004685 & 0.576520 & 0.004670 \\ 20 \% & 0.349970 & 0.004515 & 0.472160 & 0.004674 & 0.575130 & 0.004659\end{array}$

Relative PNL in vivo system detector current

(source energy photons incident upon detectors/source photon)

$\begin{array}{ccccccc}\% \text { change } & 0.200 \mathrm{MeV} & 3 \sigma & 0.662 \mathrm{MeV} & 3 \sigma & 1.460 \mathrm{MeV} & 3 \sigma \\ -20 \% & 0.048100 & 0.000635 & 0.065894 & 0.000751 & 0.081321 & 0.000829 \\ -10 \% & 0.048164 & 0.000636 & 0.065995 & 0.000752 & 0.081490 & 0.000831 \\ -5 \% & 0.048165 & 0.000636 & 0.066006 & 0.000752 & 0.081529 & 0.000832 \\ 0 \% & 0.048046 & 0.000202 & 0.065956 & 0.000237 & 0.081499 & 0.000269 \\ 5 \% & 0.048031 & 0.000648 & 0.065909 & 0.000751 & 0.081476 & 0.000831 \\ 10 \% & 0.048047 & 0.000649 & 0.065953 & 0.000752 & 0.081554 & 0.000832 \\ 20 \% & 0.048167 & 0.000636 & 0.066159 & 0.000754 & 0.081796 & 0.000834\end{array}$

Relative PNL 29-cm NaI detector current

(source energy photons incident upon 29-cm NaI detector/source photon)

$\begin{array}{ccccccc}\% \text { change } & 0.200 \mathrm{MeV} & 3 \sigma & 0.662 \mathrm{MeV} & 3 \sigma & 1.460 \mathrm{MeV} & 3 \sigma \\ -20 \% & 0.016496 & 0.000381 & 0.023209 & 0.000453 & 0.029184 & 0.000508 \\ -10 \% & 0.016539 & 0.000382 & 0.023278 & 0.000454 & 0.029282 & 0.000510 \\ -5 \% & 0.016551 & 0.000382 & 0.023312 & 0.000455 & 0.029338 & 0.000510 \\ 0 \% & 0.016479 & 0.000119 & 0.023265 & 0.000140 & 0.029343 & 0.000158 \\ 5 \% & 0.016566 & 0.000383 & 0.023367 & 0.000456 & 0.029415 & 0.000503 \\ 10 \% & 0.016617 & 0.000384 & 0.023427 & 0.000457 & 0.029473 & 0.000504 \\ 20 \% & 0.016674 & 0.000385 & 0.023532 & 0.000452 & 0.029629 & 0.000507\end{array}$


Experiment \#5C

Vary the source concentration of the thorax, pelvis, and arms.

Relative BOMAB surface current

(source energy photons/source photon)

$\begin{array}{ccccccc}\% \text { change } & 0.200 \mathrm{MeV} & 3 \sigma & 0.662 \mathrm{MeV} & 3 \sigma & 1.460 \mathrm{MeV} & 3 \sigma \\ -20 \% & 0.356400 & 0.004491 & 0.479190 & 0.004744 & 0.582450 & 0.004718 \\ -10 \% & 0.354370 & 0.004571 & 0.476950 & 0.004722 & 0.580150 & 0.004699 \\ -5 \% & 0.353410 & 0.004559 & 0.475650 & 0.004709 & 0.579090 & 0.004691 \\ 0 \% & 0.352097 & 0.001479 & 0.473819 & 0.001564 & 0.577123 & 0.001558 \\ 5 \% & 0.351810 & 0.004538 & 0.473570 & 0.004688 & 0.576510 & 0.004670 \\ 10 \% & 0.350800 & 0.004525 & 0.472760 & 0.004680 & 0.575570 & 0.004662 \\ 20 \% & 0.348920 & 0.004501 & 0.471060 & 0.004805 & 0.574000 & 0.004649\end{array}$

Relative PNL in vivo system detector current (source energy photons incident upon detectors/source photon)

$\begin{array}{ccccccc}\text { \% change } & 0.200 \mathrm{MeV} & 3 \sigma & 0.662 \mathrm{MeV} & 3 \sigma & 1.460 \mathrm{MeV} & 3 \sigma \\ -20 \% & 0.048064 & 0.000649 & 0.065761 & 0.000750 & 0.081046 & 0.000827 \\ -10 \% & 0.048156 & 0.000636 & 0.065942 & 0.000752 & 0.081393 & 0.000830 \\ -5 \% & 0.048142 & 0.000635 & 0.065947 & 0.000752 & 0.081467 & 0.000831 \\ 0 \% & 0.048046 & 0.000202 & 0.065956 & 0.000237 & 0.081499 & 0.000269 \\ 5 \% & 0.048081 & 0.000635 & 0.065969 & 0.000752 & 0.081570 & 0.000832 \\ 10 \% & 0.048144 & 0.000636 & 0.066083 & 0.000753 & 0.081716 & 0.000834 \\ 20 \% & 0.048162 & 0.000636 & 0.066198 & 0.000755 & 0.081927 & 0.000811\end{array}$

Relative PNL 29-cm NaI detector current (source energy photons incident upon 29-cm NaI detector/source photon)

$\begin{array}{ccccccc}\text { \% change } & 0.200 \mathrm{MeV} & 3 \sigma & 0.662 \mathrm{MeV} & 3 \sigma & 1.460 \mathrm{MeV} & 3 \sigma \\ -20 \% & 0.015084 & 0.000367 & 0.021313 & 0.000435 & 0.026915 & 0.000484 \\ -10 \% & 0.015926 & 0.000377 & 0.022462 & 0.000445 & 0.028293 & 0.000501 \\ -5 \% & 0.016257 & 0.000380 & 0.022906 & 0.000447 & 0.028841 & 0.000502 \\ 0 \% & 0.016479 & 0.000119 & 0.023265 & 0.000140 & 0.029343 & 0.000158 \\ 5 \% & 0.016857 & 0.000384 & 0.023762 & 0.000456 & 0.029885 & 0.000511 \\ 10 \% & 0.017174 & 0.000392 & 0.024170 & 0.000464 & 0.030400 & 0.000511 \\ 20 \% & 0.017703 & 0.000393 & 0.024929 & 0.000471 & 0.031342 & 0.000527\end{array}$


APPENDIX C. RESULTS IN GRAPHICAL FORM
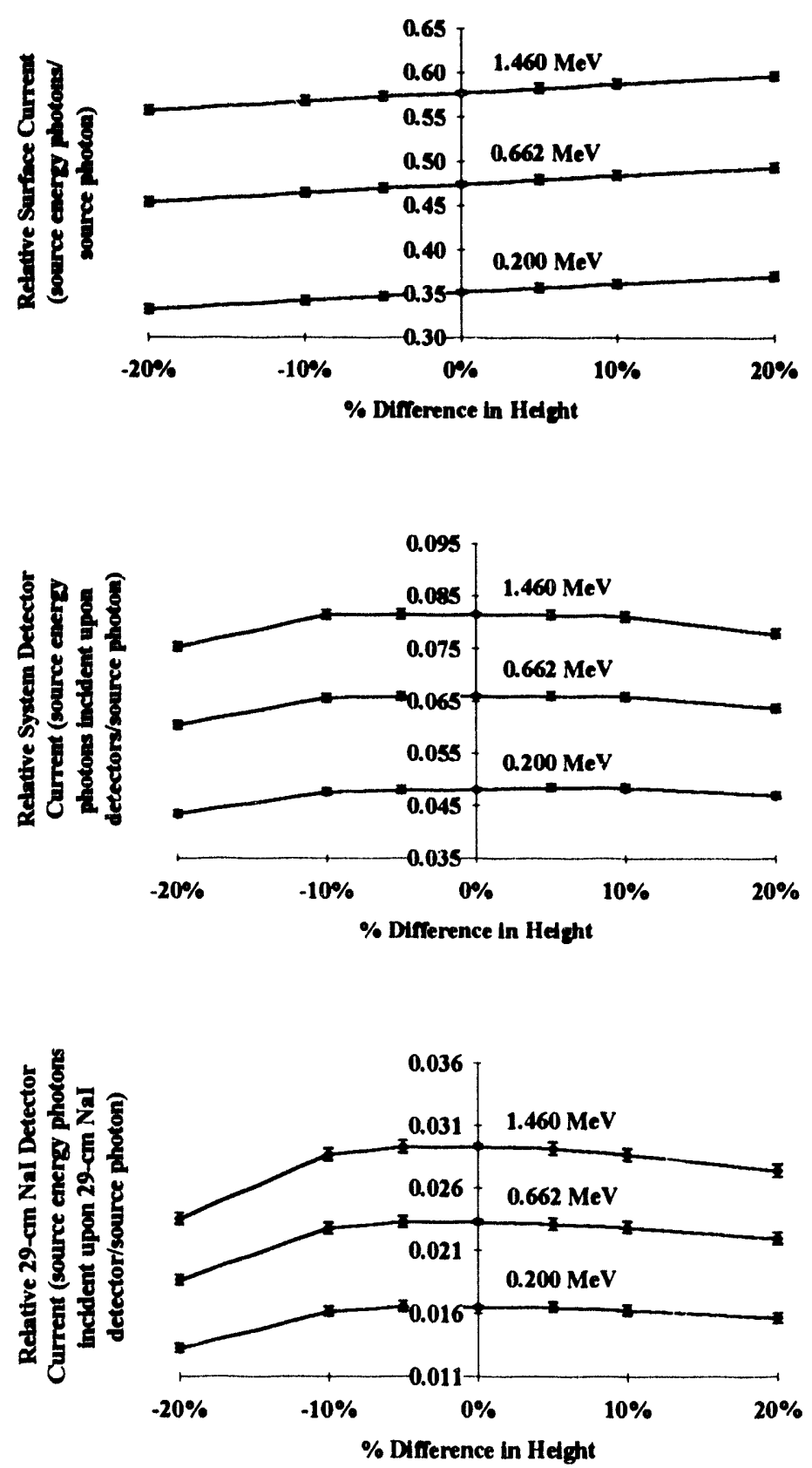

Fig. C.1. Monte Carlo results for different phantom heights (Experiment \#1). Errors shown are $\pm 3 \sigma$. 

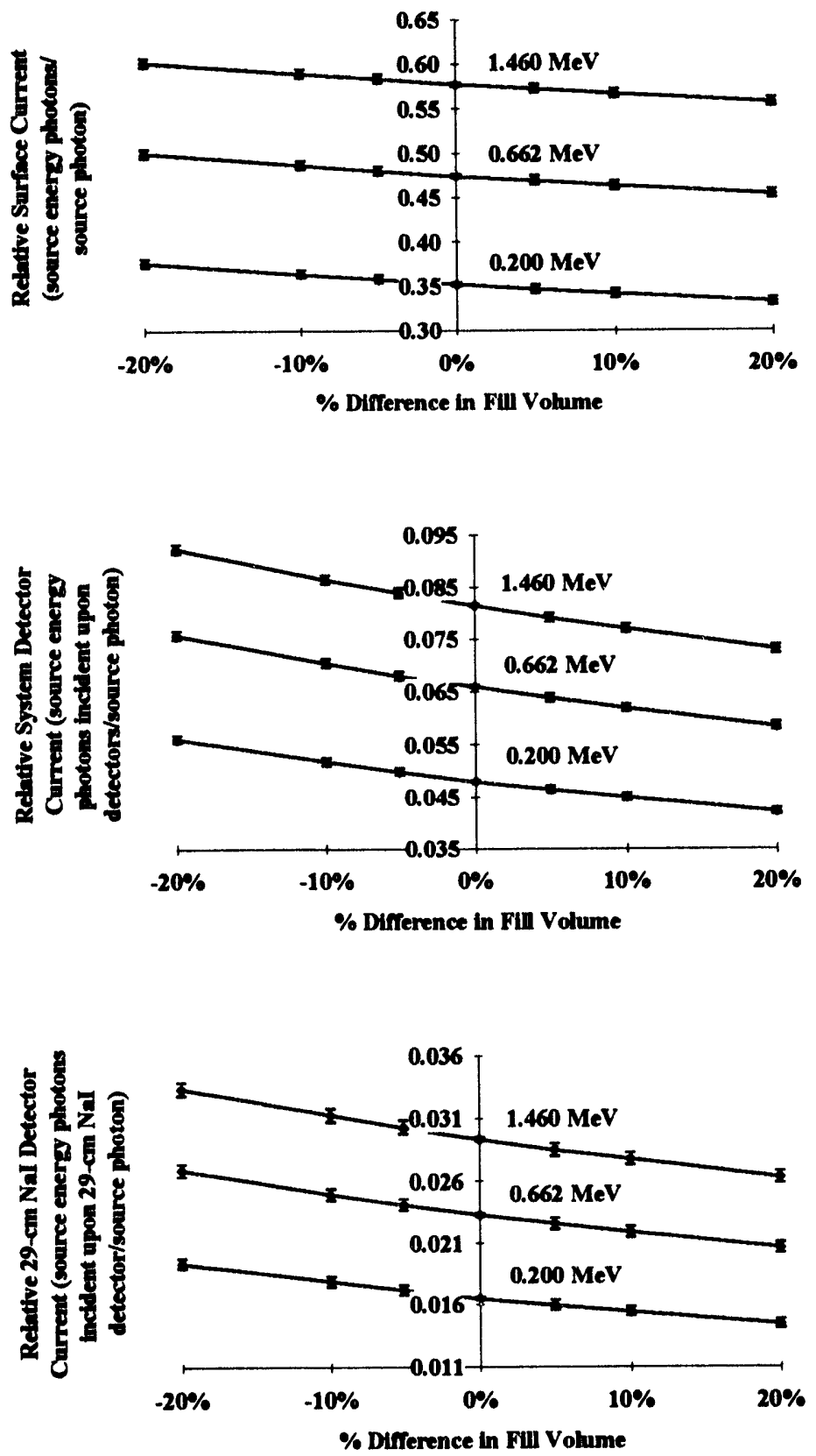

Fig. C.2. Monte Carlo results for different fill volumes of the phantom; hold the height constant (Experiment $\# 2 A)$. Errors shown are $\pm 3 \sigma$. 

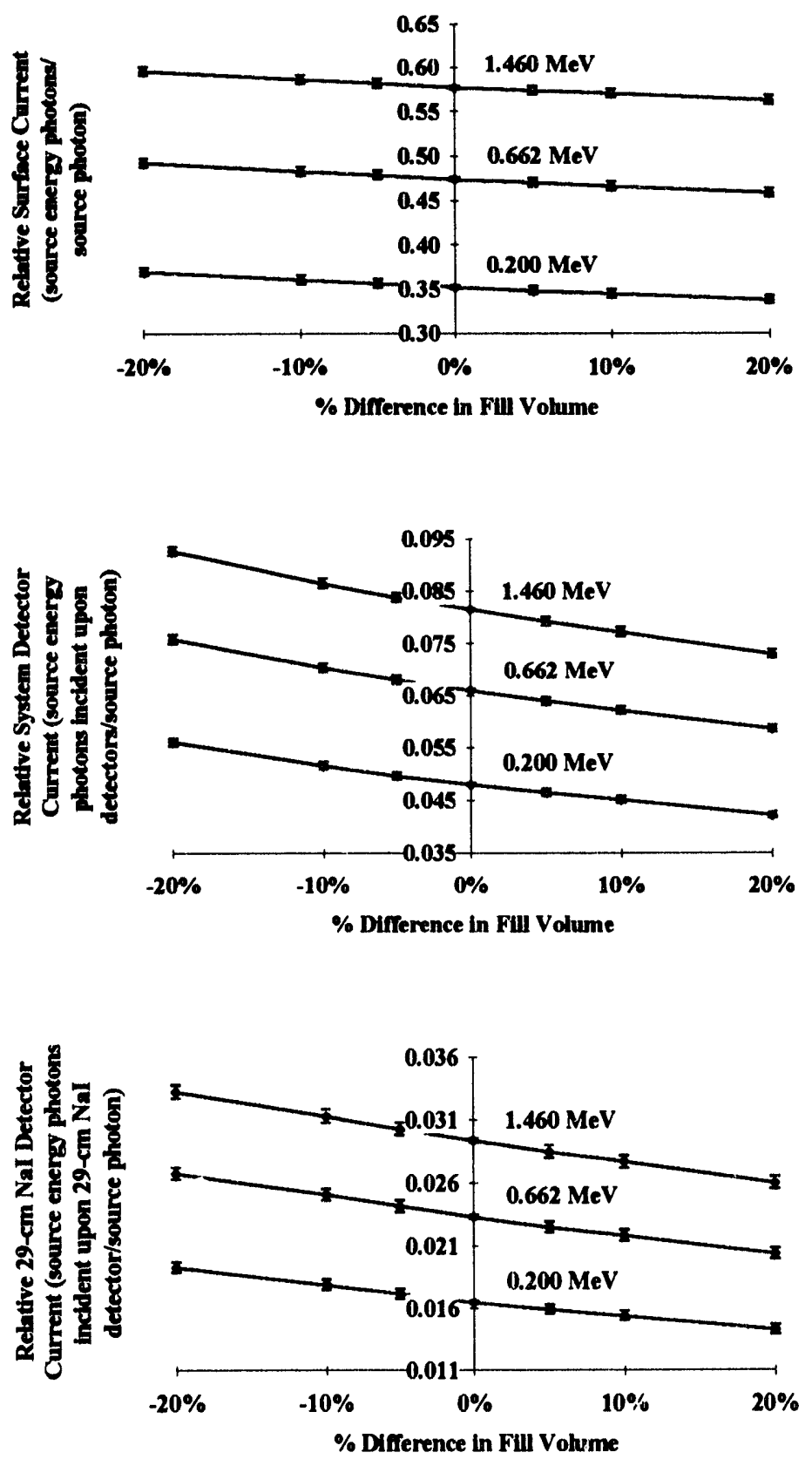

Fig. C.3. Monte Carlo results for different fill volumes of the phantom; vary the height proportionately (Experiment \#2B). Errors shown are $\pm 3 \sigma$. 

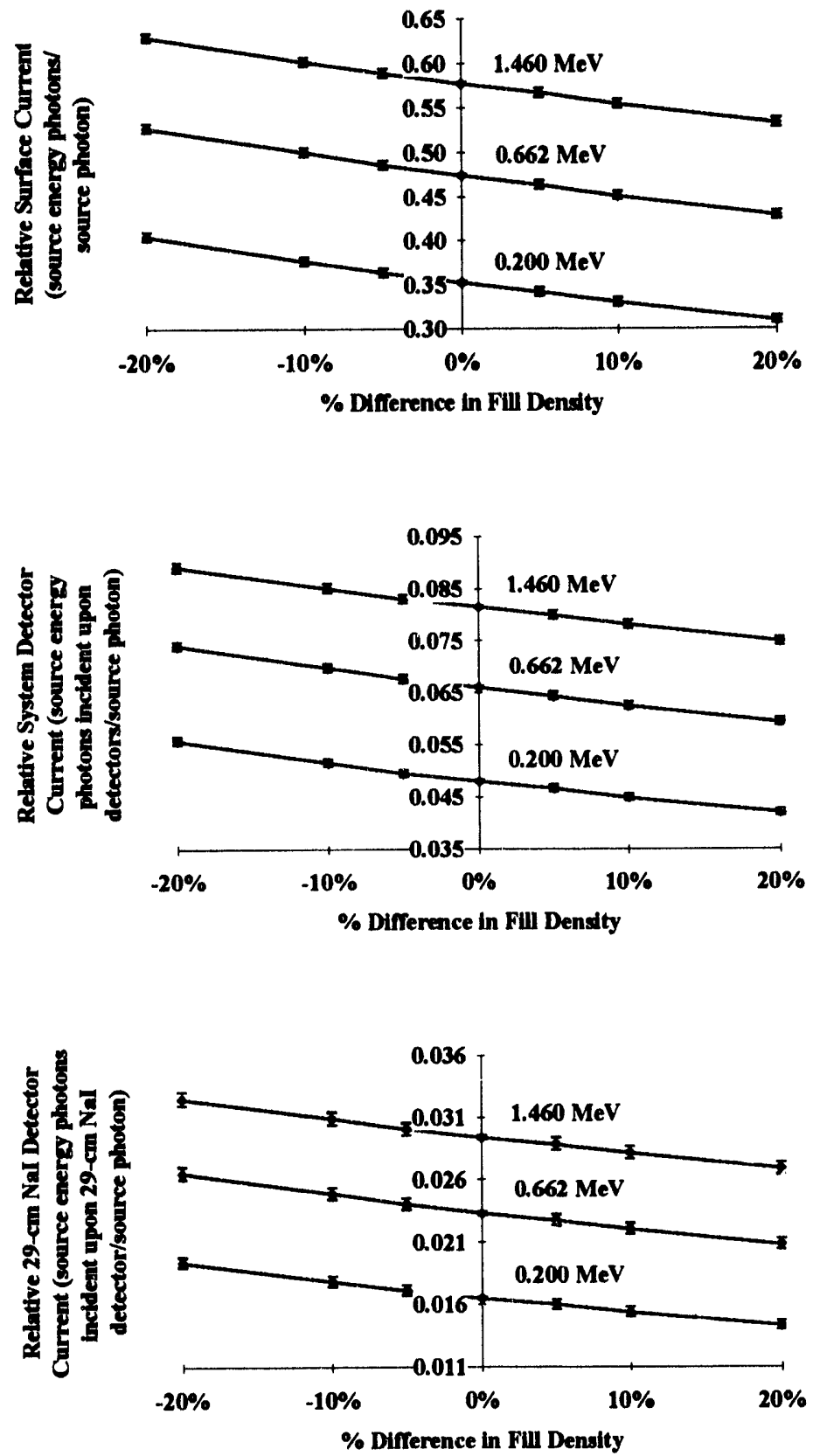

Fig. C.4. Monte Carlo results for different densities of the polyurethane fill material (Experiment \#3A). Errors shown are $\pm 3 \sigma$. 

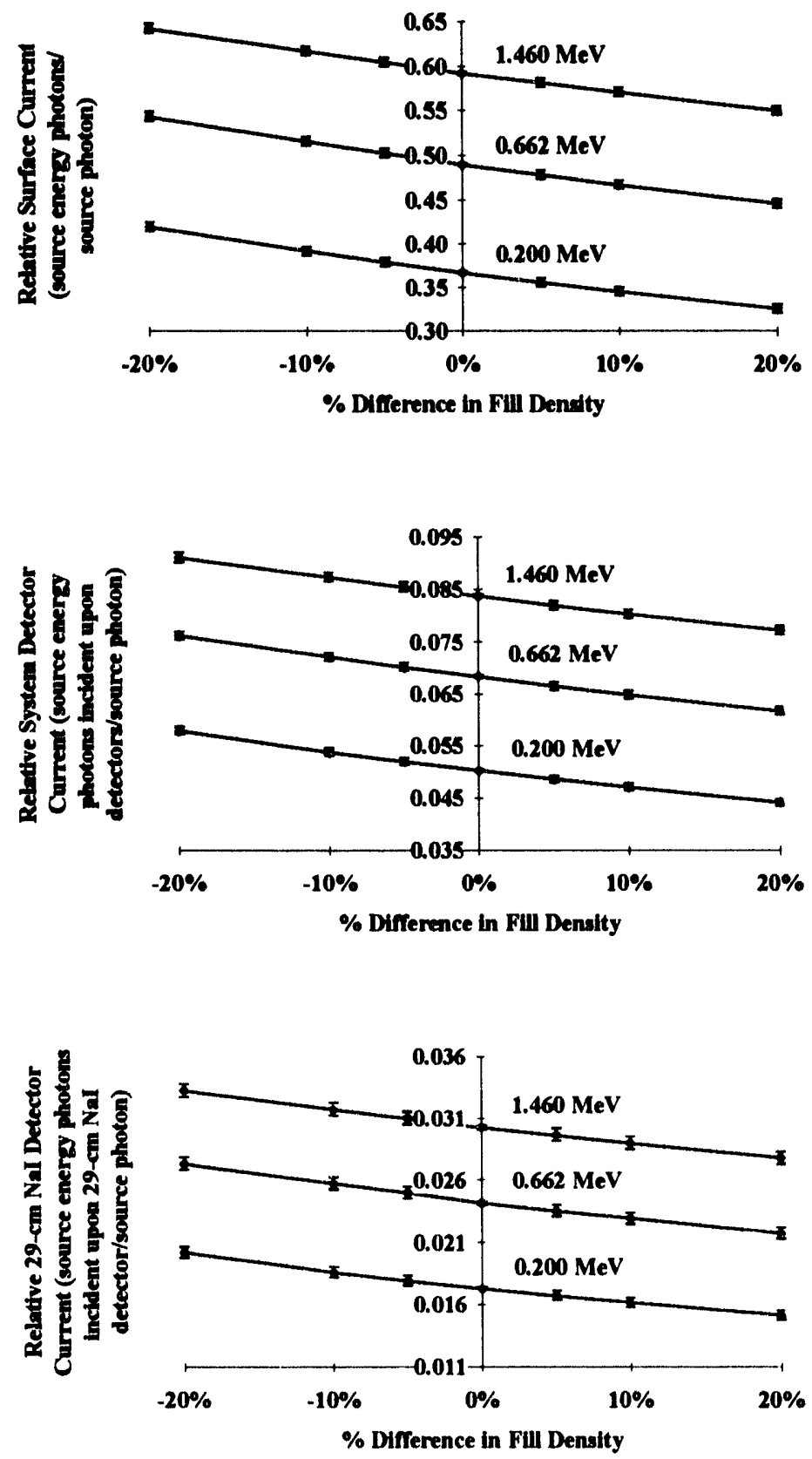

Fig. C.5. Monte Carlo results for different densities of the water fill material (Experiment $\# 3 B$ ). Errors shown are $\pm 3 \sigma$. 

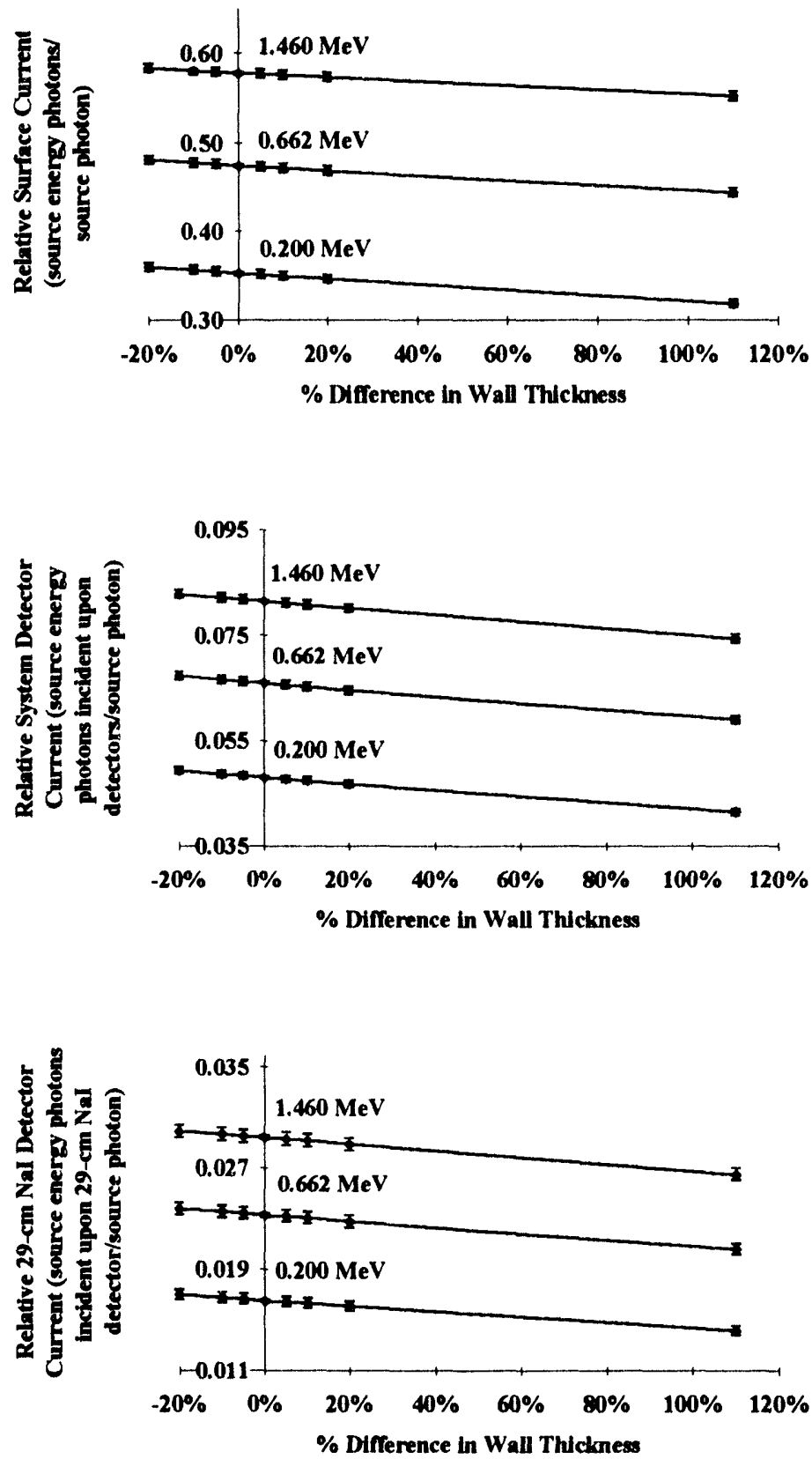

Fig. C.6. Monte Carlo results for different wall thicknesses of the phantom (Experiment \#4). Errors shown are $\pm 3 \sigma$. 

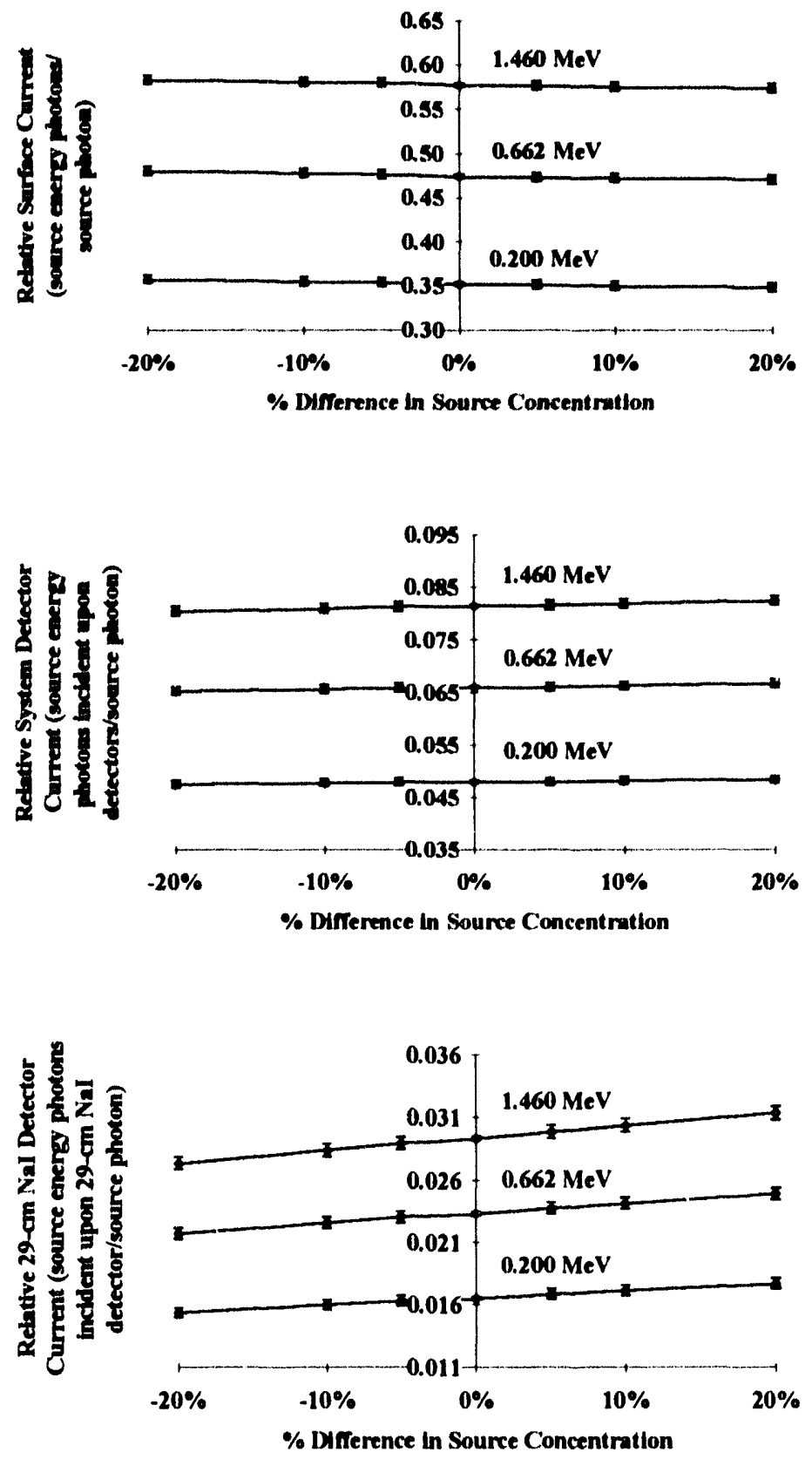

Fig. C.7. Monte Carlo results for different source concentrations of the thorax (Experiment \#5A). Errors shown are $\pm 3 \sigma$. 

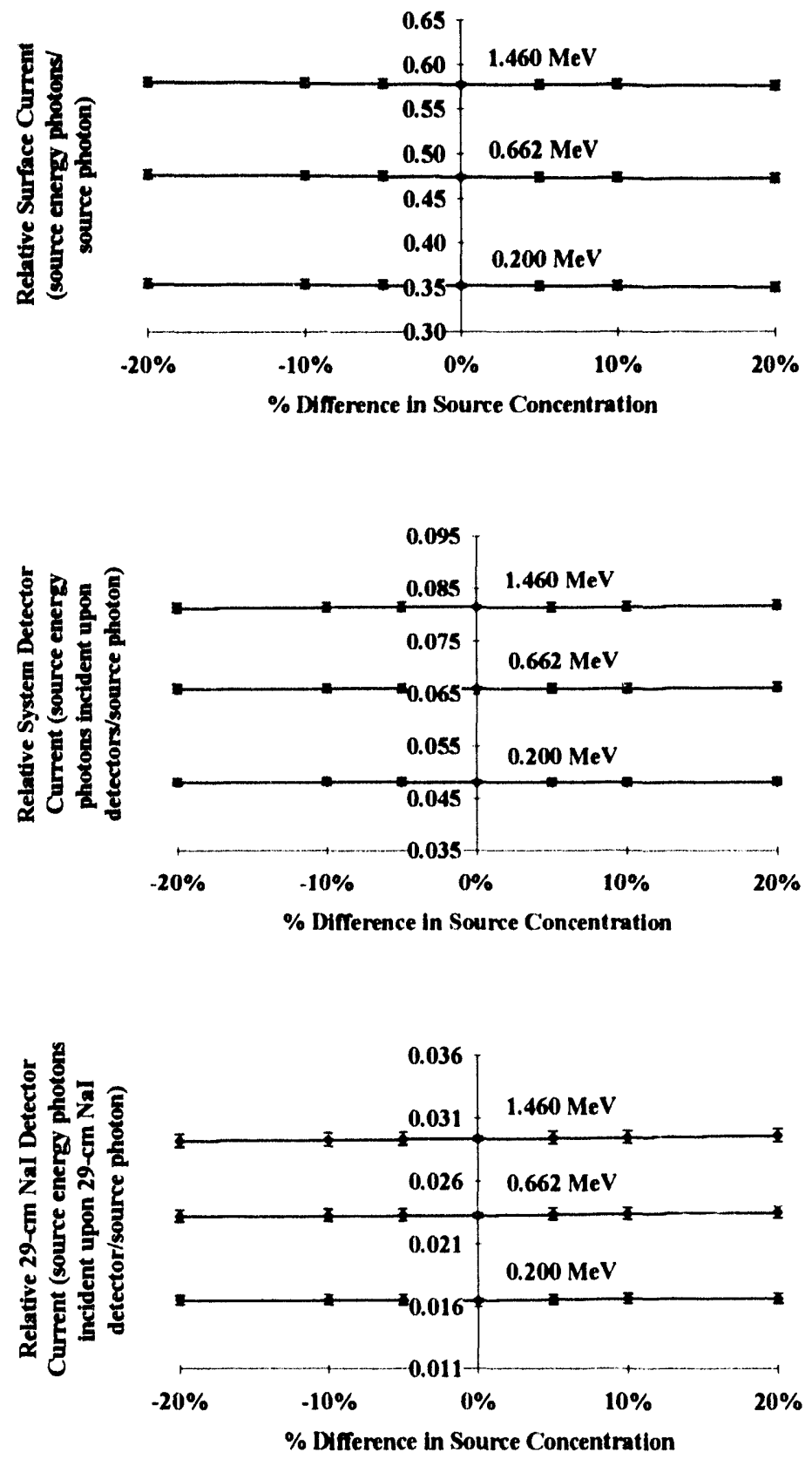

Fig. C.8. Monte Carlo results for different source concentrations of the pelvis (Experiment \#5B). Errors shown are $\pm 3 \sigma$. 

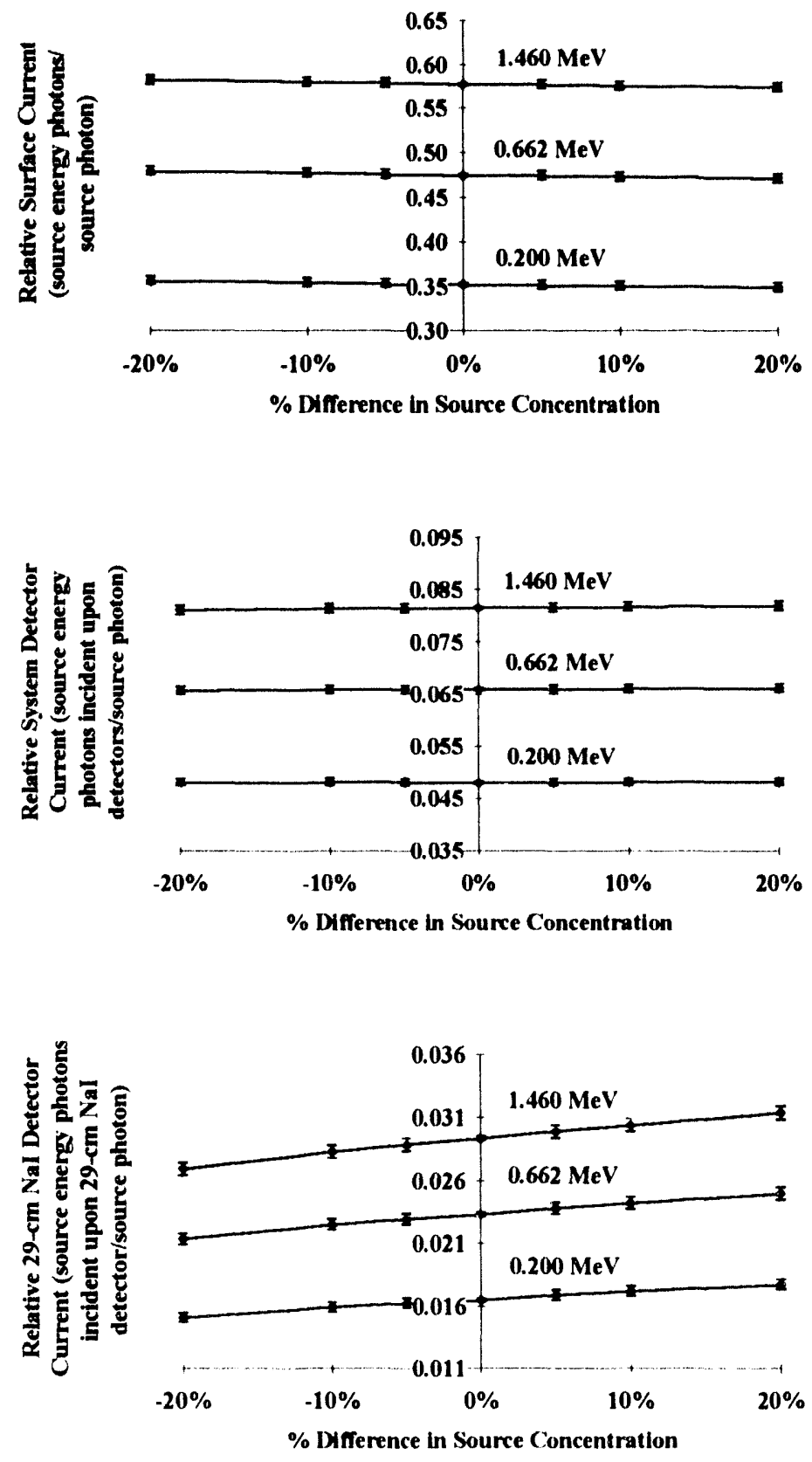

Fig. C.9. Monte Carlo results for different source concentrations of the thorax, pelvis, and arms (Experiment \#5C). Errors shown are $\pm 3 \sigma$. 

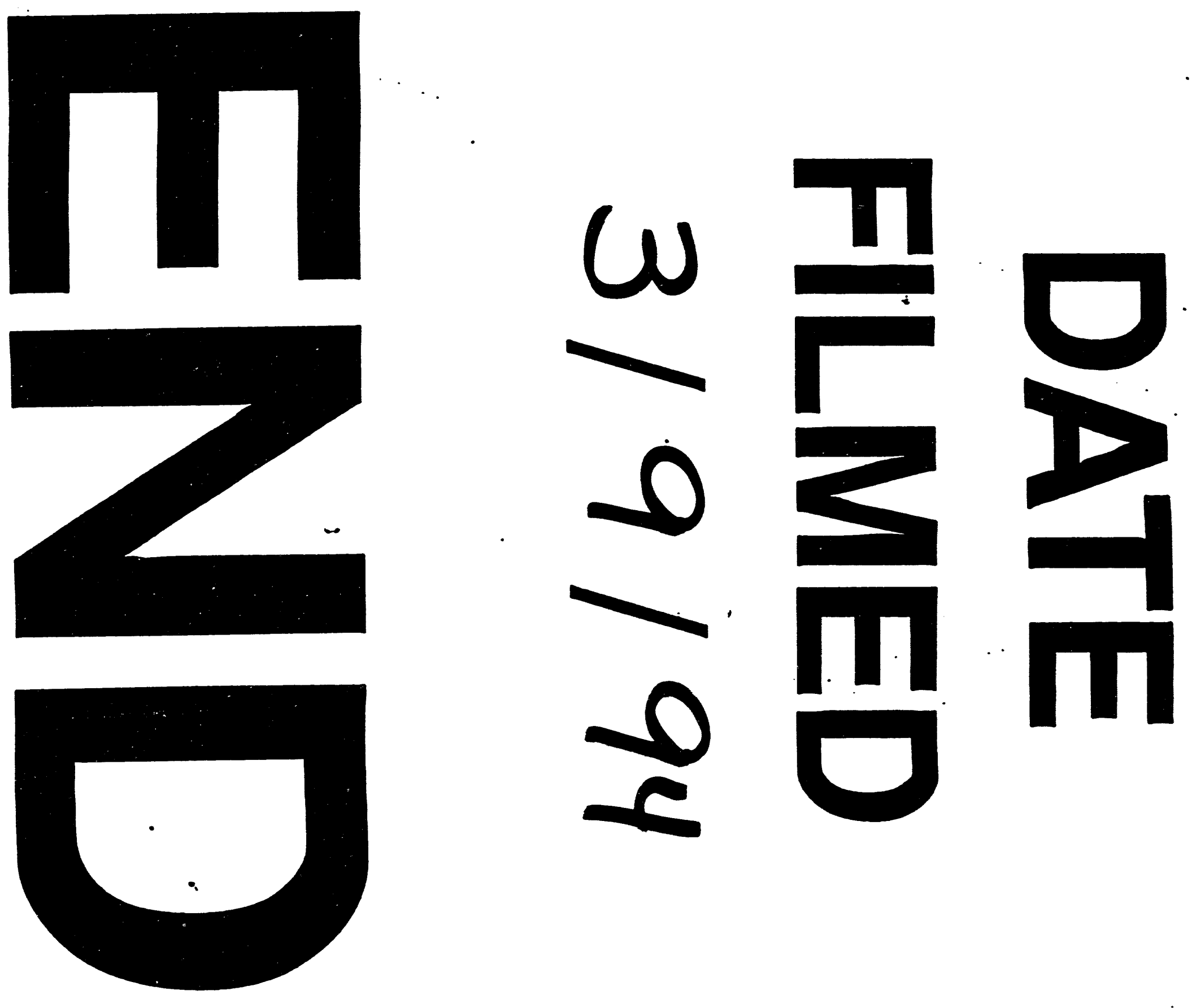
